\title{
Application of Nanosatellites for Lunar Missions
}

\author{
Andrea Bellome \\ Cranfield University \\ Bedford, MK10 9JB, UK \\ Andrea.Bellome@cranfield.ac.uk
}

\author{
Louis Leng \\ Cranfield University \\ Bedford, MK10 9JB, UK \\ Louis.Leng@cranfield.ac.uk \\ Suchetan Mummigatti \\ Cranfield University \\ Bedford, MK10 9JB, UK \\ Suchetan.Mummigatti@cranfield.ac.uk
}

\author{
Aydin Nakhaee-Zadeh \\ Cranfield University \\ Bedford, MK10 9JB, UK \\ Aydin.Nakhaeezadeh- \\ Gutierrez@cranfield.ac.uk
}

\author{
Matthew Coyle \\ Immense Simulations \\ Milton Keynes, UK \\ Mattcoyle48@gmail.com \\ Zaria Serfontein \\ Cranfield University \\ Bedford, MK10 9JB, UK \\ Z.Serfontein@cranfield.ac.uk
}

\author{
Guillermo Zaragoza Prous \\ Cranfield University \\ Bedford, MK10 9JB, UK \\ G.Zaragoza-Prous@cranfield.ac.uk
}

\author{
Sharon D'Souza \\ Cranfield University \\ Bedford, MK10 9JB, UK \\ Sharon.D-Souza@cranfield.ac.uk
}

Two major themes for the space sector in recent years have been the resurgence of missions to the Moon, facilitating the expansion of human presence into the Solar System, and the rapid growth in CubeSat launches. Lunar missions will play an important role in sustainable space exploration, as discussed in the Global Exploration Roadmap. The Roadmap outlines the next steps for the current and next generation of explorers and reaffirms the interest of 14 space agencies to return to the Moon. Over the past decade, a more daring approach to space innovation and the proliferation of low-cost small satellites have invited commercialization and, subsequently, have accelerated the development of miniaturized technologies and substantially reduced the costs associated with CubeSats. In this context, CubeSats are increasingly being considered as platforms for pioneering missions beyond low-Earth orbit. This paper describes a $3 \mathrm{U}$ nanosatellite mission to the Moon, designed as part of the UKSEDS Satellite Design Competition, capable of capturing and analysing details of the lunar environment. To achieve the primary mission objectives, a camera and an infrared spectrometer have been included to relay information about historic lunar landmarks to Earth. The design was developed to be integrated with Open Cosmos' OpenKit and reviewed by experts in the field from SSPI. The paper includes a detailed assessment of the current state of miniaturized instruments and the quality of scientific return which can be achieved by a lunar CubeSat mission. This concludes in an overall feasibility study of lunar CubeSats, a discussion of the current limitations and challenges associated with CubeSat technologies and a framework for future missions.

\section{TABLE OF CONTENTS}

1. INTRODUCTION .................................................... 1

2. UKSEDS SATELLITE DESIGN COMPETITION ..... 2

3. SELENE MISSION DESIGN................................... 3

4. SELENE PAYLOAD DESIGN ................................ 5

5. DISCUSSION ….......................................................... 12

6. CONCLUSION ............................................................. 13

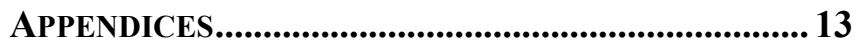

A. LUNAR LANDMARKS............................................ 14
B. MisSION ASSUMPTIONS AND REQUIREMENTS ..14 ACKNOWLEDGEMENTS ...........................................15

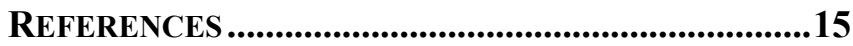

BIOGRAPHY ...................................................................18

\section{INTRODUCTION}

In recent years, two major themes for the space sector have been the growth of the small satellite sector, in particular

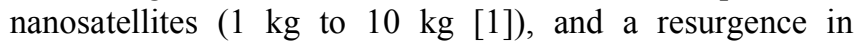
missions to the Moon and Mars. The proliferation of low-cost small satellites has invited commercialisation and subsequently, has rapidly reduced the costs associated with offering satellite-based services. Advancements in nanosatellite technologies have made space more accessible to all, allowing for infinite possibilities in space mission architectures to support the diverse requirements of the space community. In the past decade, nanosatellite launches have increased rapidly from less than 20 launches a year in 2010 to more than 400 launches predicted for 2020 [2][3]. Of the standardised CubeSat research spacecraft, the $3 \mathrm{U}$ and $6 \mathrm{U}$ platforms are currently the most popular sizes. Traditional satellites have been expensive to build and launch and therefore, the significant reduction in costs associated with CubeSats have made them an attractive alternative [4]. Although most of the nanosatellites launched to date have been to low Earth orbit (LEO) for applications such as remote sensing or communications, they are now being used for interplanetary missions as well.

At the same time, there has been an increased interest in returning to the Moon and Mars. The Global Exploration Roadmap, created by the International Space Exploration Coordination Group (ISECG), is the result of global collaboration and reaffirms the interest of 14 space agencies, including the European Space Agency (ESA), the National Aeronautics and Space Administration (NASA) and the Japan Aerospace Exploration Agency (JAXA), to expand the presence of humans into the solar system [5]. The complexity 
of missions involved in the return of humans to the Moon, and the eventual human exploration of Mars, will require an unprecedented level of autonomy and robotic support [6]. In preparation for this need, CubeSats are an ideal platform for technology demonstration missions and are increasingly being considered as platforms for pioneering missions beyond LEO. As part of NASA's 2024 Moon Missions, they have included calls for CubeSats missions and plan to utilise CubeSats to map the size and distribution of frozen reservoirs in the lunar South Pole, and demonstrate entry into a near rectilinear highly elliptical halo orbit over the Moon's poles [7]. Additionally, nanosatellites could potentially be used as part of constellations for applications including communications, surveying the lunar surface, and creating a lunar Global Positioning System [8].

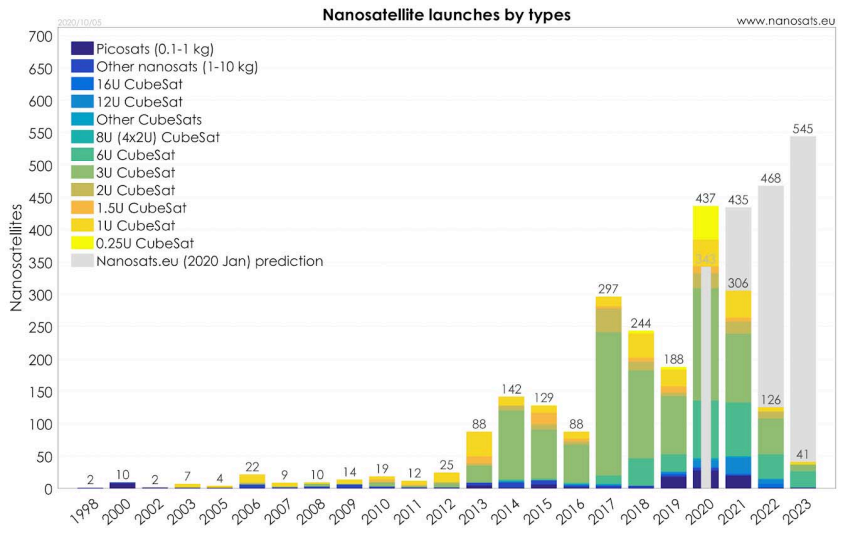

Figure 1: Exponential Increase in Number of Nanosatellite Launches [2]

Although CubeSats are relatively low in cost and quick to deploy, they have several limitations which limit the overall performance of the spacecraft. Due to their size limits, CubeSats have a significant lack of available power [9] and cannot carry large payloads. Miniaturised electronics, which are more sensitive to radiation, and reduced on-board propulsion capabilities contribute to the short lifetimes of CubeSats. The mission designed in this report is highly relevant to the current space environment and addresses some of the questions relating to the limitations of CubeSat platforms. This paper describes a $3 \mathrm{U}$ nanosatellite mission to the Moon, assessing the current status of miniaturised instruments and subsystems and determining the quality of scientific return which can be achieved by a lunar CubeSat mission. This concludes in an overall feasibility study of lunar CubeSats, discussing the challenges associated with CubeSat technologies and outlining a framework for future missions.

\section{UKSEDS SATELLITE DESIGN COMPETITION}

The Satellite Design Competition is an annual competition organised by the United Kingdom Students for the Exploration and Development of Space (UKSEDS) society and invites students to design, construct and operate a nanosatellite payload system [10]. Students pass through a rigorous review process with panels of experts within the space industry, developing their designs from design to manufacture and testing their performance in a simulated lunar environment. The 2019-2020 competition was sponsored by Space \& Satellite Professionals International (SSPI) and Open Cosmos (OC). SSPI provided mentors to the competing teams and reviewed the rules and requirements documentation [11], ensuring the goals were achievable and a reflection of the current interests of the space sector. In addition to reviewing the competition framework, OC enabled the expansion of the competition to include a build phase where selected teams would be able to integrate their payload on-board OC's 3U OpenKit platform. Due to the ongoing Covid-19 pandemic, the competition was restructured, and the Build and Test phase of the competition was replaced with an extended design report, focusing on adapting the baseline design to an actual mission. Students were still able to use OC's OpenApp software to support the mission design portion of the competition.

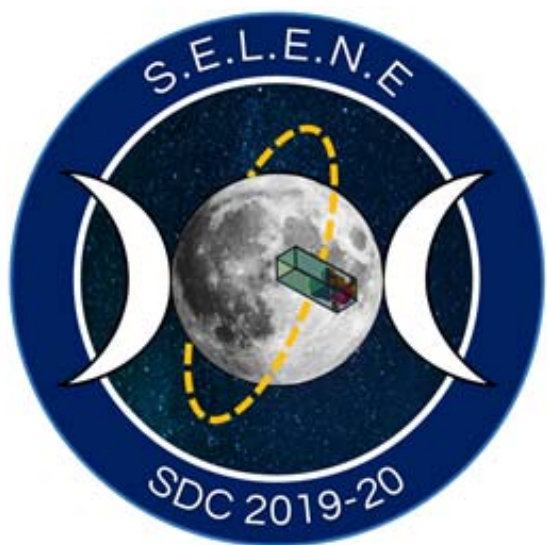

Figure 2: SELENE Mission Patch

The authors of this paper were members of the Simulated Environment Lunar Expeditions Nanosat Experiment (SELENE) team, comprised of students from around the world, currently studying at Cranfield University (Astronautics and Space Engineering, Space Masters and PhDs in Aerospace), and young professionals from Milton Keynes. Since the competition had an underlying lunar theme, the satellite was named after Selene, the Greek goddess of the Moon. SELENE's primary mission was to design a nanosatellite capable of detecting, identifying, analysing and relaying information, regarding a predetermined list of lunar landmarks, to Earth. The mission was optimised to maximise the number of revisits to each historic lunar landmark.

The result of this project was a $3 \mathrm{U}$ CubeSat design, integrated with OC's 3U OpenKit, which in turn is equipped with deployable solar arrays, an attitude control system, and a communication and power subsystem. Designed to launch in 2025, ridesharing aboard an Ariane 6 rocket to enter a lunar orbit, the payload subsystem consists of a camera, an infrared (IR) spectrometer, and a thruster, included for stationkeeping. An X-band antenna was included in the original 
design, but removed due to mass, data and volume constraints. The CubeSat will orbit the Moon, capturing data with the scientific payload and transmitting it to Earth by way of a communication relay satellite in a low-lunar orbit (LLO). The CubeSat will operate for at least 3 months, up to 2 years, in which time it will observe 10 historic lunar landmarks (see Appendix A). Upon completion of the mission, the satellite will de-orbit by means of a lunar impact.
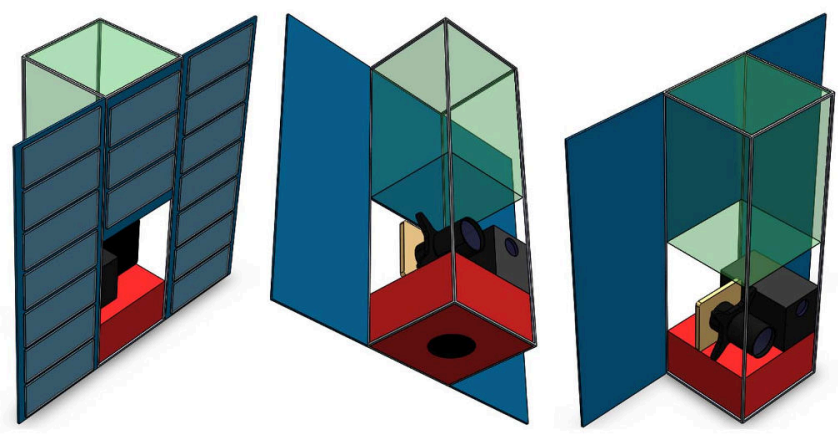

Figure 3: Final Satellite Design with Solar Arrays, Power and Communications Module (Green), Camera, IR Spectrometer, and Thruster (Red)

Mission Objectives and Requirements

\section{Primary Objectives}

The mission shall detect, identify, analyse and

OB-1 relay good quality data of Lunar landmarks during nominal operation

The CubeSat's injection orbit will maximise

OB-2 revisit times to increase the amount of data acquired from the mission

\section{Secondary Objectives}

The mission shall be used to assess the quality

OB-3 of scientific return a CubeSat can achieve for a Lunar mission

A detailed list of mission requirements, operational requirements, constraints, and assumptions made during the design process are included in Appendix B. These were an amalgamation of objectives given by the competition organisers, subsequently derived requirements and design constraints given by OC. The following section will summarise the final design of the SELENE 3U lunar nanosatellite and highlight the current challenges associated with the $3 \mathrm{U}$ CubeSat platform. The purpose of this paper is to assess the current state of miniaturised payload instruments and quantify the quality of scientific return which can be achieved by a lunar CubeSat mission.

\section{SELENE MISSION DESIGN}

Due to the limited mass capabilities of CubeSats, designing trajectories for outer space missions (e.g. towards the Moon or Solar System planets) is a challenging task for two main reasons:
- Escape trajectories can require high propellant consumption through expensive manoeuvres (i.e. $\Delta v)$

- Once the spacecraft is placed in orbit around the target body, orbit maintenance is usually required for addressing scientific objectives

This section will focus on the design of the transfer trajectory towards the Moon, as well as the lunar orbit needed for the SELENE science phase.

\section{Lunar Transfer Options}

To assess the feasibility of solving the first challenge, i.e. reaching the Moon with limited propellant consumption, SELENE mission explored two different options:

- Direct transfer with rideshare towards low-lunar orbit

- Low-energy transfer from Sun-Earth L2 Halo orbit

Both options heavily depend upon rideshare opportunities in the SELENE mission timeframe (i.e. 2022+). However, after NASA's MarCO mission [12] demonstrated the interplanetary capabilities of CubeSats, rideshare opportunities towards Moon and Solar System planets are likely to be available (see for example [13] and [14]). A European launch vehicle is preferable, since the payload will be integrated into the OpenKit and tested in ESA member states before flight. The primary launch provider selected is the Ariane 6, which is due to be operational in the near future and will launch from Kourou in French Guiana [15]. It offers flexibility for small satellite launches, as they can piggyback with primary payloads at a lower cost. A call for rideshare is now open for a 2023 lunar transfer orbit insertion [16]. The United Launch Alliance's (ULA) Atlas V launcher [17], with its Centaur upper stage, is the backup launch provider selected for this mission, and will launch from Cape Canaveral, USA. The launcher is expected to be functional in 2021, thus fulfilling the project's launch requirement. ULA

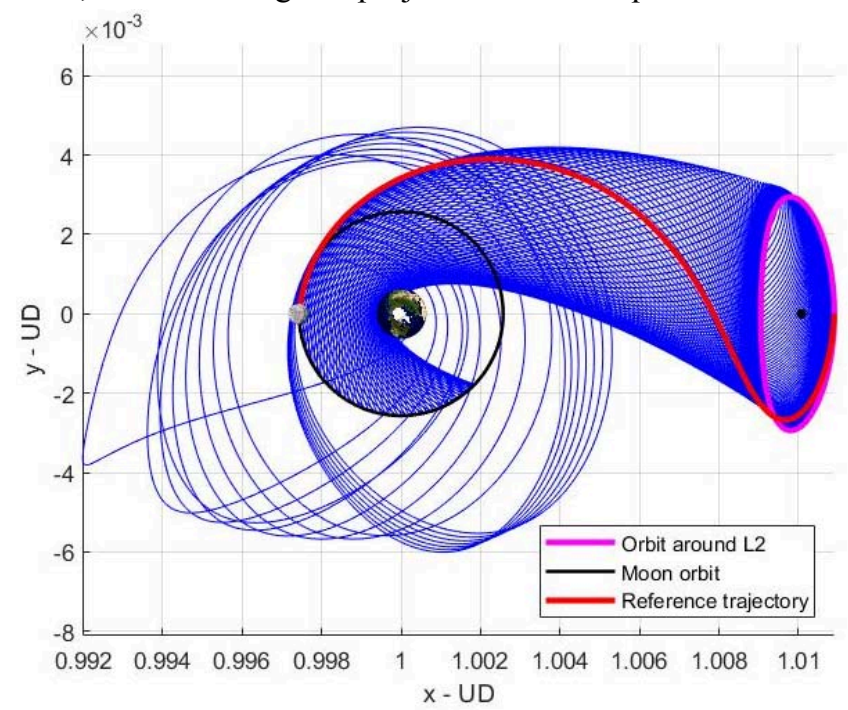

Figure 4: Unstable Invariant Manifold for the Reference Orbit 
offers CubeSat rideshare opportunities, which could be utilised for SELENE, in standard CubeSat dispensers with their piggyback launches. A launch could be booked several months in advance if ULA announces a call for CubeSats Rideshare, or they could be approached at least a year before the launch with a request for a possible rideshare option. In recent years, there has been an increase in private launchers offering services to CubeSats. Rocket Lab's Electron and Virgin Galactic's LauncherOne are two such services that could potentially be used for insertion into lunar orbit, as well as Momentus Space's Ardoride [18] reusable vehicle, able to transfer spacecraft from LEO to LLO within 3-6 months.

The second option for the SELENE mission consists of a lowenergy transfer from the Sun-Earth L2 Halo orbit towards an LLO. The Sun-Earth Lagrange points have been targeted by scientific missions for Sun and outer space observations (see for example SOHO [19] and LISA pathfinder [20] for missions targeting L1 Halo orbits, or Gaia [21] targeting L2 orbits). Rideshare opportunities towards Lagrange points orbits can arise, for example, in the late 2020s with NASA's WFIRST [22] and ESA's M4 mission ARIEL [23]. Small propulsive manoeuvres exerted in the unstable direction of Halo orbits permit spacecraft to find the so-called unstable invariant manifold of the given orbit, i.e. the set of all trajectories propagated in the unstable direction.

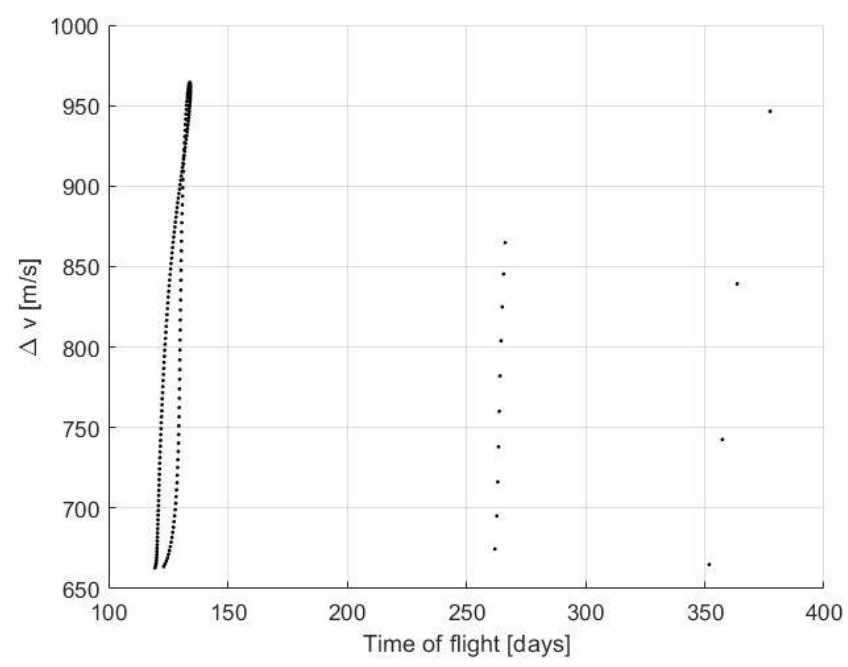

Figure 5: Total $\Delta v$ Opportunities for SELENE with Respect to Time of Flight

A planar ARIEL-like L2 Halo orbit $(\sim 26,000 \times 86,000 \mathrm{~km})$ is taken as reference for the SELENE mission (see Figure 4); the planar approximation is useful for quick computation of the $\Delta v$ required by the SELENE spacecraft, without the need for computing complex 3D transfers. Further research will be focused on a full 3D model for a more detailed design. The unstable invariant manifold is propagated up until the spacecraft encounters the Moon orbit. A patched-conic approach is then used to compute the $\Delta v$ needed for orbit insertion. Figure 4 shows the departing Halo orbit, the unstable invariant manifold and the reference trajectory for the SELENE mission. Figure 5 highlights the $\Delta v$ and time of flight opportunities for injecting the spacecraft into a $30 \times 216$ $\mathrm{km}$ altitude lunar orbit for the Moon encounter options identified by the unstable invariant manifold expansion. Quasi Frozen Orbit

The orbit selected for the SELENE science mission is a polar $30 \times 216 \mathrm{~km}$ altitude quasi-frozen orbit [24] (see Figure 6), with the periselene directly over the lunar south pole. The quasi-frozen condition ensures that the eccentricity and the argument of periapsis drift due to lunar non-spherical gravity effects remains bounded (see Figure 7 and Figure 8 representing the eccentricity and semi-major axis variation over a propagation of 30 days). In particular, the eccentricity remains between 0.04 and 0.049 , and the semi-major axis varies between $1858.30 \mathrm{~km}$ and $1860.72 \mathrm{~km}$. This condition allows for near-zero $\Delta v$ needed for station-keeping $(\sim 10-15$ $\mathrm{m} / \mathrm{s}$ per month based on previous mission heritage [25]).

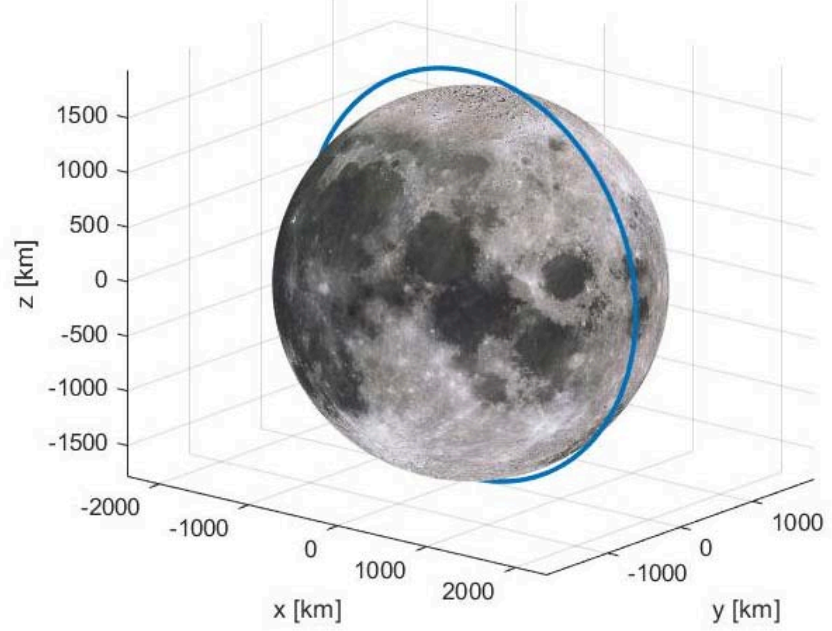

Figure 6: SELENE Quasi-Frozen Lunar Orbit

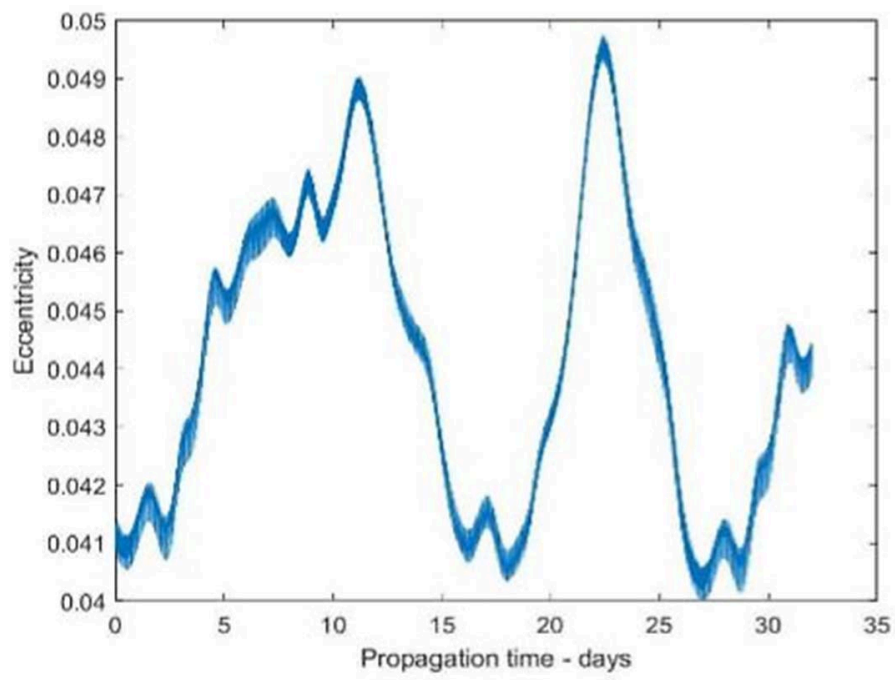

Figure 7: Eccentricity Variation for SELENE Mission 


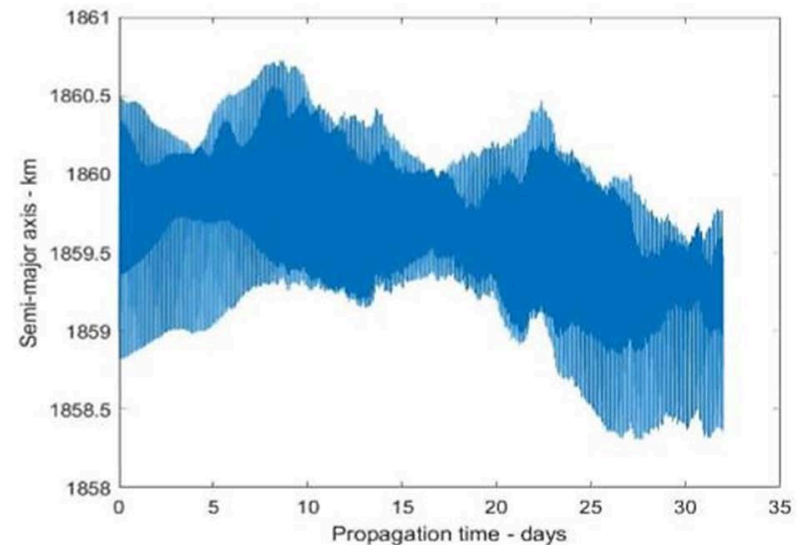

Figure 8: Semi-Major Axis Variation for SELENE Science Orbit

\section{Regulations}

The regulatory challenges faced in the deployment of a lunar CubeSat are very similar to those of a geocentric deployment. Shared hurdles include International Telecommunication Union (ITU) frequency allocation and registration, compliance with domestic launch requirements, acquisition of and compliance with required/optional insurance policies and international coordination to ensure compliance with article IX of the Outer Space Treaty [26][27]. With regards to end of life, a lunar mission would not be required to comply with Inter-Agency Space Debris Coordination Committee (IADC) and the Committee on the Peaceful Uses of Outer Space (COPUOS) space debris regulations which only cover satellites orbiting the Earth [28][29]. However, NASA's guidelines on the preservation of lunar artefacts should be followed when considering satellite disposal [30].

\section{SELENE Payload Design}

The system-level budgets have been included to give context to payload trade-offs and to highlight some restrictions with the $3 \mathrm{U}$ platform. Margins were allocated in accordance with ESA's Standard Margin Philosophy [31]. In line with this margin philosophy, a 5\% margin has been added to all offthe-shelf products and a $10 \%$ margin has been added to modified equipment.

\section{Mass Budget}

Open Cosmos allocated a mission payload mass budget of 2 $\mathrm{kg}$. As seen from Table 1, even with margins the payload is within limits. In the next iteration of the mission, it may be possible to add another instrument to the payload.

Table 1: Payload Mass Budget

\begin{tabular}{|l|c|c|c|}
\cline { 2 - 4 } \multicolumn{1}{l|}{ Component } & Mass (g) & Margin & Total (g) \\
\hline IR Spectrometer & 280 & $10 \%$ & 308.0 \\
\hline Camera & 167 & $10 \%$ & 183.7 \\
\hline Cold Iodine Thruster & 900 & $5 \%$ & 945.0 \\
\hline
\end{tabular}

\begin{tabular}{|l|l|l|}
\hline Total & & $1,436.7$ \\
\hline Total (incl. margin) & $\mathbf{2 0 \%}$ & $\mathbf{1 , 7 2 4 . 0}$ \\
\hline
\end{tabular}

\section{Power Budget}

The data handling system average power has been estimated for the OpenKit on-board processor using values from similar processors and will be continuously active. The average time over a landmark is 5 minutes. It is assumed that when the satellite is not taking measurements, it is communicating. Therefore, there are three possible power modes; science mode, communication mode and orbital maintenance mode. The peak load of the satellite will be during an orbit where the satellite must take scientific measurements, relay the data and perform a station-keeping manoeuvre.

The peak load occurs at $16.38 \mathrm{~W}$ during orbital maintenance mode, but the power never exceeds the OpenKit limit of 18.5 $\mathrm{W}$. The maximum eclipse time during the mission is 50 minutes, total orbit time 105 minutes. If the satellite can generate enough power during the shortest sunlit period to address the peak load for a single orbit, mission operations do not have to include orbits dedicated solely to charging the batteries. Table 2 highlights the power budget for the mission.

Table 2: System Power Budget

\begin{tabular}{|c|c|c|c|}
\hline Science Mode & $\begin{array}{c}\text { Power } \\
\text { (W) }\end{array}$ & Margin & $\begin{array}{c}\text { Total Power } \\
\text { (W) }\end{array}$ \\
\hline IR Spectrometer & 1.47 & $10 \%$ & 1.62 \\
\hline Camera & 1.30 & $10 \%$ & 1.43 \\
\hline Data Handling & 3.00 & $5 \%$ & 3.15 \\
\hline \multicolumn{3}{|l|}{ Total } & 6.20 \\
\hline \multicolumn{2}{|l|}{ Total (incl. margin) } & $20 \%$ & 7.44 \\
\hline Communication & 2.00 & $5 \%$ & 2.10 \\
\hline Data Handling & 3.00 & $5 \%$ & 3.15 \\
\hline \multicolumn{3}{|l|}{ Total } & 5.25 \\
\hline \multicolumn{2}{|l|}{ Total (incl. margin) } & $20 \%$ & 6.30 \\
\hline Thruster & 10.00 & $5 \%$ & 10.50 \\
\hline Data Handling & 3.00 & $5 \%$ & 3.15 \\
\hline \multicolumn{3}{|l|}{ Total } & 13.65 \\
\hline \multicolumn{3}{|l|}{ Total (incl. margin) } & 16.38 \\
\hline
\end{tabular}

With an assumed battery discharge efficiency of 0.97 and charging efficiency of 0.7 , the following values were calculated:

- Total Energy Generated by Solar Panels per Orbit (Shortest Sunlit Period): 12.15 Wh

- Total Energy Usage per Orbit (Nominal Operations): 11 Wh

- Total Energy Usage per Orbit (Worst-Case Scenario): 12.96 Wh

Required power only exceeds what the solar panels are able to provide during a worst-case orbit [maximum eclipse time, payload taking measurements over landmark ( $\sim 3 \mathrm{~W}$ for 5 minutes), continuously powering the data handling 
subsystem $(\sim 3 \mathrm{~W})$ and communications $(\sim 2 \mathrm{~W})$, and performing orbit maintenance manoeuvre $(\sim 10 \mathrm{~W}$ for 10 minutes). During nominal operations, when no thrusters are used, the energy usage per orbit will be approximately 11.17 Wh, which is within limits. Exceeding available power can be easily avoided by ensuring an orbit manoeuvre is not required on the same orbit that data is collected. If an emergency manoeuvre is required, the payload sensors will be temporarily paused for one orbit to allow the batteries to recharge. In an emergency, all non-essential subsystems will be powered down to allow the batteries to recharge to capacity.

\section{Data Budget}

The data budget for the satellite is divided into stored data and transmitted data (see Tables 3 and 4). Since the acquired data is pre-processed before transmission, the size of the stored data and transmitted data differs. The final size of the data storage required is smaller than the $4 \mathrm{~GB}$ the OpenKit provides, thus additional storage would not be needed.

Although the antenna payload was not included as part of the mission, it is represented here to show the amount of data it would require and highlights one of variables which led to the payload being removed from the design. The X-band antenna and the IR Spectrometer record data continuously for 5 minutes, which corresponds to the time of a landmark pass, and the camera captures one image per second during those 5 minutes. The size of the camera images are $6 \mathrm{MB}$, with a resolution of $2014 \times 1536$ pixels with a 10-bit pattern (which is traduced to 16 bits for storage [32]). The data storage required for the $\mathrm{X}$-band antenna is calculated from the measurements it returns, at a rate of $65 \mathrm{Mbps}$. A safety margin of $20 \%$ was included in both budgets to account for possible errors and disconnections in the transmission.

Table 3: Storage Data Budget

\begin{tabular}{|l|c|c|c|}
\cline { 2 - 4 } \multicolumn{1}{c|}{ Component } & $\begin{array}{c}\text { Component } \\
\text { Storage } \\
\text { (GB) }\end{array}$ & $\begin{array}{c}\text { Data Rate } \\
\text { Recording } \\
\text { (GB/s) }\end{array}$ & $\begin{array}{c}\text { Total } \\
\text { Data } \\
\text { (GB) }\end{array}$ \\
\hline IR Spectrometer & 0 & 0.000028 & 0.0085 \\
\hline Camera & 2 & 0.006 & 1.75 \\
\hline Total & 2 & 0.00603 & 1.76 \\
\hline Total + Margin & $\mathbf{2}$ & $\mathbf{0 . 0 1}$ & $\mathbf{2 . 1 2}$ \\
\hline Antenna & 0 & 0.008 & 2.38 \\
\hline $\begin{array}{l}\text { Total + Margin } \\
\text { + Antenna }\end{array}$ & $\mathbf{2}$ & $\sim \mathbf{0 . 0 1 8}$ & $\mathbf{4 . 5}$ \\
\hline
\end{tabular}

Table 3 shows the storage data budget, while Table 4 represents the data per landmark to be transmitted from the satellite to the relay orbiter. The data will be qualitatively filtered and compressed to minimize the transmission data budget and the time of communication (accounting for a given uplink data rate of $4 \mathrm{kbps}$ ). For each landmark, the two best images will be selected according to typical image features. Following selection, the on-board software will compress all the sensor data with a lossless compression algorithm. The compression ratio for this type of algorithm is approximately 2:1 [33] (up to $3: 1$ in a best-case scenario). The separation of operations into two passes was due to the location of the instruments on the satellite. During the first pass, only the IR spectrometer and the camera will be facing the lunar surface, and during the second pass, the recording sensor will be the X-band antenna.

Table 4: Transmission Data Budget

\begin{tabular}{|l|c|c|}
\cline { 2 - 3 } \multicolumn{1}{c|}{} & $\begin{array}{c}\text { Compressed } \\
\text { Data per Pass } \\
\text { (MB) [2:1 ratio] }\end{array}$ & $\begin{array}{c}\text { Transmission } \\
\text { Time (h) }\end{array}$ \\
\hline IR Spectrometer & 4.25 & 2.5 \\
\hline Camera & 6 & 3.4 \\
\hline Total (Pass 1) & 10.25 & 5.9 \\
\hline Total + Margin & $\mathbf{1 2 . 3}$ & $\mathbf{7 . 0 8}$ \\
\hline X-Band Antenna & 1218.75 & 693.3 \\
\hline Total (Pass 2) & 1218.75 & 693.3 \\
\hline Total + Margin & $\mathbf{1 4 6 2 . 5}$ & $\mathbf{8 3 2}$ \\
\hline
\end{tabular}

The data accounting for the attitude and orbit control system (AOCS), and any other subsystems provided by Open Cosmos, have not been included in the data budget. As can be seen from Table 4, if the X-band antenna were still part of the payload, the transmission budget would be two orders of magnitude higher. This is one of the reasons why the antenna was removed from the design. For the final design, only one pass is required to collect all the necessary data.

\section{Payload Design}

This section provides a brief overview of the selected sensors, tasked with observing lunar landmarks, integrated into the 1.5U available OpenKit payload space. As part of the final design, a camera, an IR spectrometer and an X-band antenna were investigated to achieve all the mission objectives. Due to data, mass and volume constraints, the X-band antenna was removed from the design and replaced with a thruster, required for orbital maintenance.

Previously flown LEO CubeSats included camera payloads to capture images of Earth. A camera on-board this CubeSat would satisfy the mission requirement of capturing visual data of the landmarks. The selected camera for this mission is the Nanocam C1U by GomSpace [32], chosen primarily for its mass and power characteristics, and its compatibility with the OpenKit platform. Nanocam C1U has reasonable visibility up to $650 \mathrm{~km}$ altitude and is sufficiently compact for the available payload volume in the CubeSat. It is capable of its own data processing and has a storage capacity of $2 \mathrm{~GB}$. The lens is a $1 / 2 "$ (4:3) format colour CMOS sensor, capturing images with 2048 x 1536 pixels. For its integration into the CubeSat, the lens stand will be replaced to reduce its volume. For an actual mission, having a camera on-board could have several useful applications, including mapping the lunar surface, selecting landing locations, and identifying areas of interest for future missions. 
Past lunar missions have used sensors to map the lunar surface within the infrared (IR) spectrum. Most notably, these include the Apollo 17 mission, where the lunar surface temperature was recorded while the spacecraft was in orbit [34] and the Lunar Reconnaissance Orbiter (LRO) mission, which utilised the 'Diviner Lunar Radiometer Experiment' to produce the first ever global map of thermal emissions on the Moon's surface, including its diurnal and seasonal variability [35][36]. Literature suggests that mapping the entire infrared spectrum of the Moon could be a means of identifying surface mineralogy, through the analysis of special features, since different chemical compounds found in the lunar soil would emit different ranges of visible to near-infrared radiation [37][38][39]. Due to the highly diagnostic absorption features in this wavelength region, the emitted radiation is sensitive to the surface mineralogy. Therefore, optical instruments, such as spectrometers, could be used to identify the mineralogical composition of the lunar surface, including the composition of regolith or crater edges [40].

Figure 9 shows the reflectance of typical lunar minerals, which include mafic minerals (rich in magnesium and iron), such as pyroxene [41] and olivine. These have their characteristic absorption in the near infrared region, which varies with composition within the respective locations. On average, minerals such as high-calcium pyroxene and olivine have strong absorption near $1000 \mathrm{~nm}$, whereas plagioclase has absorption at $1250 \mathrm{~nm}$. By varying the different bands of the spectrum, the composition of the minerals could be discerned from the received reflected signal.

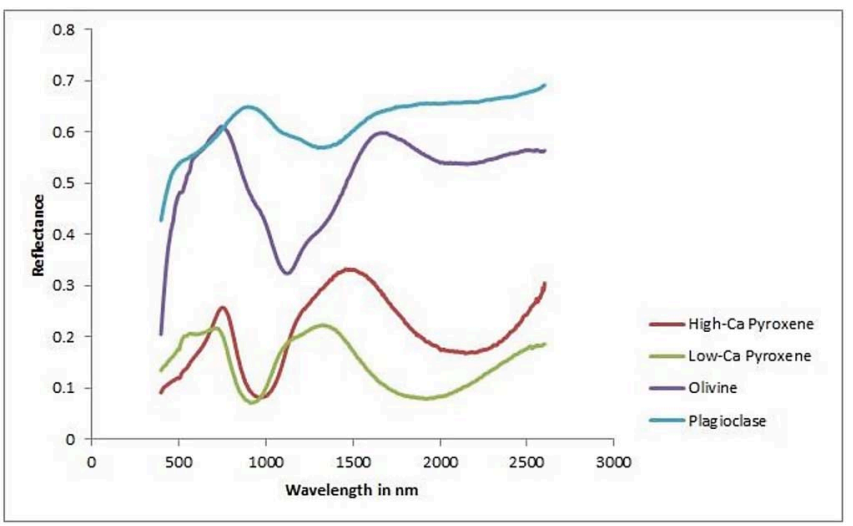

Figure 9: Reflectance Spectra of Typical Lunar Minerals

Since humans will be returning to the lunar surface in the near future, this information would be beneficial in the planning phase of crewed settlements. With the IR spectrometer, it would be possible to identify areas with useful resources and create a thermal map of the lunar surface, aiding in the identification of future lunar base locations.

Within the competition limitations, requiring the payload to be commercially available and less than 1U, an Argus-1000 Infrared Spectrometer [42] was chosen as the optimal instrument for the final design. With a size of 45x50x80 mm and a mass of approximately $280 \mathrm{~g}$, the sensor can fit into the desired CubeSat volume envelope, while allowing adequate space for the other instruments. Its functional spectral wavelength $(0.7-1.7 \mu \mathrm{m}$, up to $2.4 \mu \mathrm{m})$ allows for the detection of the range of radiances emitted by the mineral compositions that are of interest.

\section{X-Band Antenna}

The lunar soil is composed mainly of fine grains, formed as a result of environmental degradation over time. Due to the lack of a thick atmosphere, the lunar surface suffers much more damage from the space environment compared to the Earth's surface. The roughness of the lunar surface can be obtained from the information provided by Synthetic Aperture Radar (SAR) independently of the environmental light. This data will reveal the structure of the different parts which form the landmarks (floors, walls, rim, peak, ejecta, and rays). X-band SAR is a powerful tool for landmark analysis and therefore, the implementation and validation of this technology in a CubeSat platform will be a valuable objective.

The development of SAR antennas for the CubeSat platform is a relatively new area of research and has little flight heritage. The main problem with using SAR in CubeSats is the sizing. SAR requires long antennas to achieve a high resolution. Additionally, pulse radars require high peak power that cannot be provided by typical $3 \mathrm{U}$ power systems. Preliminary design of the X-band SAR has been done by applying the design methodology for SmallSats [43]. The parameters that defined the X-band SAR are presented in Table 5. The feasibility study concluded that the sizing constraints do not allow for the integration of a SAR payload on a $3 \mathrm{U}$ CubeSat using existing technology [44].

\section{Table 5: SAR Properties}

\begin{tabular}{|l|c|l|c|}
\hline Bandwidth & $12 \mathrm{MHz}$ & Centre Frequency & $11.2 \mathrm{GHz}$ \\
\hline Peak Power & $190 \mathrm{~W}$ & Spatial Resolution & $10 \mathrm{MHz}$ \\
\hline DC Power & $60 \mathrm{~W}$ & Swath Width & $11 \mathrm{~km}$ \\
\hline Pulse Length & 10 & Pulse Frequency & $400 \mathrm{~Hz}$ \\
\hline Incident Angle & 12 & Data Rate & $65 \mathrm{Mbps}$ \\
\hline Antenna Width & $0.3 \mathrm{~m}$ & Antenna Length & $1.5 \mathrm{~m}$ \\
\hline
\end{tabular}

\section{Attitude and Orbit Control System (AOCS)}

The competition organisers included details of the on-board AOCS, which consists of three reaction wheels, to give a pointing accuracy of 0.5 degrees, and sun sensors. As aforementioned, a thruster needed to be included for orbit maintenance. To meet the satellite requirements of $\sim 10-15$ $\mathrm{m} / \mathrm{s}$ of $\Delta v$ per month to stabilise the orbit, the team chose a cold iodine thruster developed by a French company, ThrustMe [45]. The I2T5 is a self-contained unit with its own propellant storage, flow control, power processing unit, thermal management and intelligent operation and fits within a $0.5 \mathrm{U}$ form factor. With a total $\Delta v$ of approximately $83 \mathrm{~m} / \mathrm{s}$, the I2T5 will have enough thrust to perform the necessary station-keeping manoeuvres and will still have enough remaining propellant at end of life for a de-orbiting manoeuvre. Since there is mass, volume and power left in the 
systems budgets, there is potential to collaborate with ThrustMe in customising the thruster and increasing its total wet mass. This would allow for the mission to be extended, resulting in an increase in scientific return.

\section{Data Handling}

The on-board software's main responsibilities are to acquire data from the sensors and to control the on-board actuators. Additionally, the subsystem will forward the information to the ground station and define the commands available depending on the status of the state machine of the system. The satellite has an embedded microprocessor provided by Open Cosmos [46] to control and monitor on-board devices. The payload will only record data while passing over the landmarks and afterwards, the processor will prepare the data for transmission.

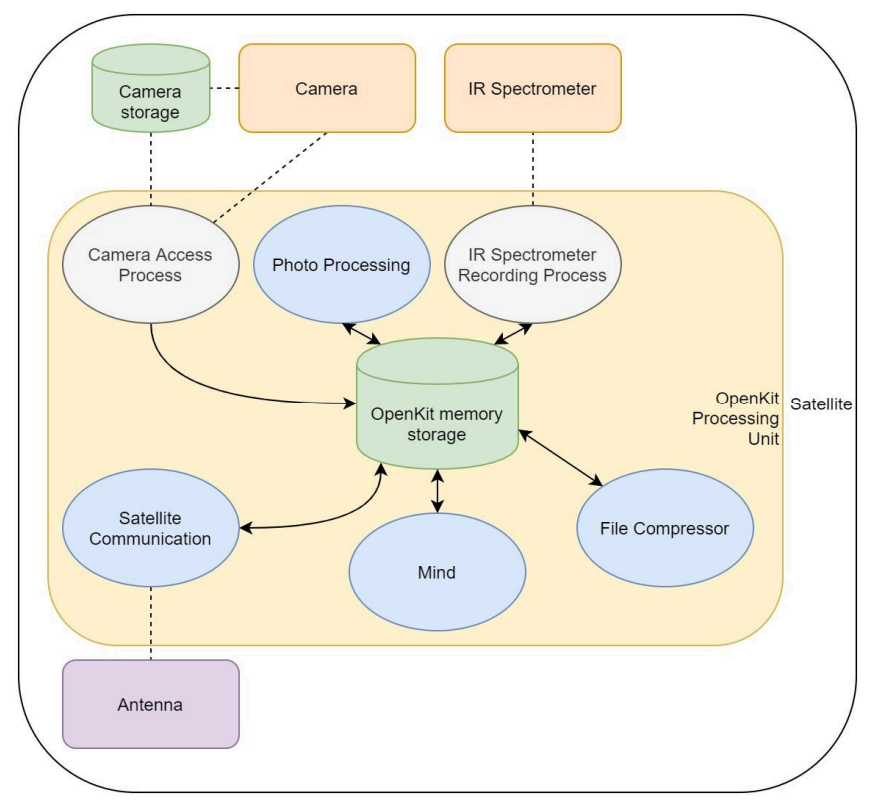

Figure 10: Node Based Software Architecture

The on-board computer will have a node-based software architecture (see Figure 10). The nodes are separated into two types: sensor access and recording processes (grey) and information processing processes (blue). This divides the software depending on its purpose, making it easier to implement and test. The main purposes of the processing nodes are:

- Photo Processing node: processes the captured images per landmark and orbit and selects the most suitable images to transmit. It considers the quality of the pictures depending on contrast, brightness and other image features.

- File Compressor node: compresses the images and data files for transmission to minimise the quantity of transmitted data.

- $\quad$ Satellite Communication node: communicates with the relay satellite.
- Mind node: contains the on-board flow control machine. It decides when it is time to record, process or send information from the satellite. To do so, it is responsible for reading the locations of landmarks and assessing when they have been reached. This information is held in a configuration file on-board the satellite and can be updated at any time during the lifetime of the mission. This node also handles the received commands.

The satellite will forward information about the status of the satellite and its payload to the ground station. Each telemetry message will contain a header with the necessary fields to identify a single message and a Cyclic Redundancy Check (CRC) code at the end. The data section can be filled with any of the payload files stored on-board and the status of each component in the satellite.

\section{Table 6: Telemetry Message}

\begin{tabular}{l|c|}
\multicolumn{1}{l}{ Section Name } & \multicolumn{1}{c|}{ Size } \\
\hline Time & 128 bits \\
\hline ID Message & 16 bits \\
\hline Data Length & 32 bits \\
\hline Data & Up to 4 GB \\
\hline CRC & 16 bits \\
\hline
\end{tabular}

The satellite will be controlled from the ground station through a series of commands. Each command constitutes a command code (CC) and an argument if it is needed (see Table 7). Command messages will also contain a header like that of telemetry messages.

Table 7: Commands

\begin{tabular}{|l|c|c|c|c|}
\hline Name & CC & Argument & Type & $\begin{array}{c}\text { Size } \\
{[\text { [bits] }}\end{array}$ \\
\hline Set Mode & 0 & Mode & Enum & 2 \\
\hline $\begin{array}{l}\text { Take Camera } \\
\text { Picture }\end{array}$ & 1 & Off - On & bool & 1 \\
\hline $\begin{array}{l}\text { Change Resolution } \\
\text { Camera }\end{array}$ & 2 & $\begin{array}{c}\text { New } \\
\text { Resolution }\end{array}$ & Enum & 4 \\
\hline $\begin{array}{l}\text { Activate } \\
\text { Spectrometer }\end{array}$ & 3 & Off - On & bool & 1 \\
\hline $\begin{array}{l}\text { Get Spectrometer } \\
\text { Data }\end{array}$ & 4 & - & - & - \\
\hline $\begin{array}{l}\text { Get Last Two } \\
\text { Images }\end{array}$ & 5 & - & - & - \\
\hline $\begin{array}{l}\text { Change Landmark } \\
\text { Set }\end{array}$ & 6 & $\begin{array}{c}\text { New } \\
\text { Landmarks }\end{array}$ & File & 409600 \\
\hline Get Satellite Status & 7 & - & - & - \\
\hline
\end{tabular}

The first command serves to change the satellite mode, in case the operator needs to check the satellite or modify something on-board (e.g. the landmark set). The following 3 commands are used to control the payload of the satellite, while commands 4 and 5 are designed to allow the payload data to be downloaded. Command 6 uploads a new landmark set to the satellite, so that more landmarks can be studied. 
Command 7 requests the status of each of the components of the satellite to monitor their performance.

\section{Communications}

The communication system is composed of the CubeSat communication transmitter (antenna and transceiver), a relay communication satellite and the ground station on Earth. The CubeSat communication system has been selected based on the system limitations and the downlink needs. Within these limitations, it was not possible to communicate directly with Earth and a communication relay satellite was included in the design to amplify the signal. The analysis of the link budget has been divided into two segments: CubeSat - Relay Satellite communication and Relay Satellite - Ground Station communication.

The parameters of the CubeSat communication systems are derived from commercial off-the-shelf (COTS) components for 3U CubeSats [47] and the parameters of the relay system have been obtained from TDRS II [48] (see Table 8).

Table 8: CubeSat and Relay Satellite Segment

\begin{tabular}{|l|c|l|c|}
\hline \multicolumn{2}{|c|}{ CubeSat } & \multicolumn{2}{c|}{ Relay Satellite } \\
\cline { 1 - 2 } Power Tx & $2 \mathrm{~W}(33 \mathrm{dbm})$ & Gain & $5.2 \mathrm{dBi}$ \\
\hline Gain & $0 \mathrm{dBi}$ & $\mathrm{FN}^{1}$ & $15.1 \mathrm{~dB} / \mathrm{K}$ \\
\hline Frequency Tx & $145.8-146 \mathrm{MHz}$ & \multicolumn{2}{c}{} \\
\cline { 1 - 2 } System Losses & $1.1 \mathrm{dBi}$ & \multicolumn{1}{|c}{} \\
\cline { 1 - 2 } & \multicolumn{2}{|l}{}
\end{tabular}

The ground station selected for the analysis is in the White Sands Test Facility in New Mexico and belongs to the NearEarth Network (NEN). The downlink frequency (19.3 - 20.2 $\mathrm{GHz}$ ) was allocated according to the Electronic Communications Committee (ECC) report on the use of frequency bands [49]. The properties of the receiver and the transmitter are presented in Table 9.

Table 9: Relay Satellite and Ground Station Segment

\begin{tabular}{|l|c|l|c|}
\hline \multicolumn{2}{|c|}{ Relay Satellite } & \multicolumn{2}{c|}{ Ground Station } \\
\hline Diameter & $0.75 \mathrm{~m}$ & Diameter & $18.2 \mathrm{~m}$ \\
\hline Gain & 99.28 & Gain & 160.55 \\
\hline Frequency Tx & $\begin{array}{c}19.3 \mathrm{GHz} \\
(\mathrm{Ka}-\mathrm{Band})\end{array}$ & SNR $^{2}$ & $16 \mathrm{~dB}$ \\
\hline Bandwidth & $5 \mathrm{~dB}$ & Floor Noise & $12.6 \mathrm{~dB} / \mathrm{K}$ \\
\hline
\end{tabular}

The signal can be demodulated and modulated in Quadrature Phase Shift Keying (QPSK). For a bit error rate (BER) value

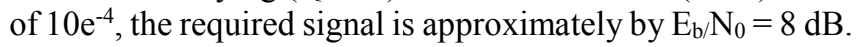
The signal arrives with a power of $-135 \mathrm{dBW}$ which leads to a margin of $94 \mathrm{dBW}$ from signal requirements.

It should be noted that the required power of the signal produced by the relay satellite to reach the ground station is lower than the received power from the CubeSat. The relay satellite operates like a signal reflector; if the CubeSat is transmitting the information within a $45 \mathrm{~km}$ range of the relay

${ }^{1}$ Floor Noise satellite, the signal will reach the ground station and the information can be demodulated. A Low Noise Amplifier (LNA), with a gain in the order of $10 \mathrm{~dB}$, can be integrated into satellite communication subsystem to increase the range to approximately $100 \mathrm{~km}$.

The quality of the signal that arrives at the ground station has been analysed by simulating the demodulation and modulation of the signal in QPSK and in the channel.

\section{Concept of Operations (CONOPS)}

The operation of the satellite was divided into five mission phases (see Figures 11 and 12):

- Launch: The satellite will be launched in early 2025 on a rideshare on Ariane 6.

- Interplanetary Phase and Transfer Manoeuvre: The satellite will be in hibernation mode until orbit insertion.

- Orbit Insertion: OC's attitude control system will stabilise the spacecraft. The team will deploy the solar panels, orient the panels to face the Sun and begin charging the batteries. Both the camera payload and IR spectrometer will be tested

- Operational Phase: The satellite will take measurements of the lunar landmarks and send the data to the relay satellite. Sending the data will take multiple orbits, during which the payload will not collect more data. Once all data has been sent, the satellite will take measurements at the next landmark. When the payload is not taking measurements, the satellite will orient the solar panels to face the Sun and charge the batteries

- End of life: The satellite will be passivated and use the remainder of its propellant to de-orbit

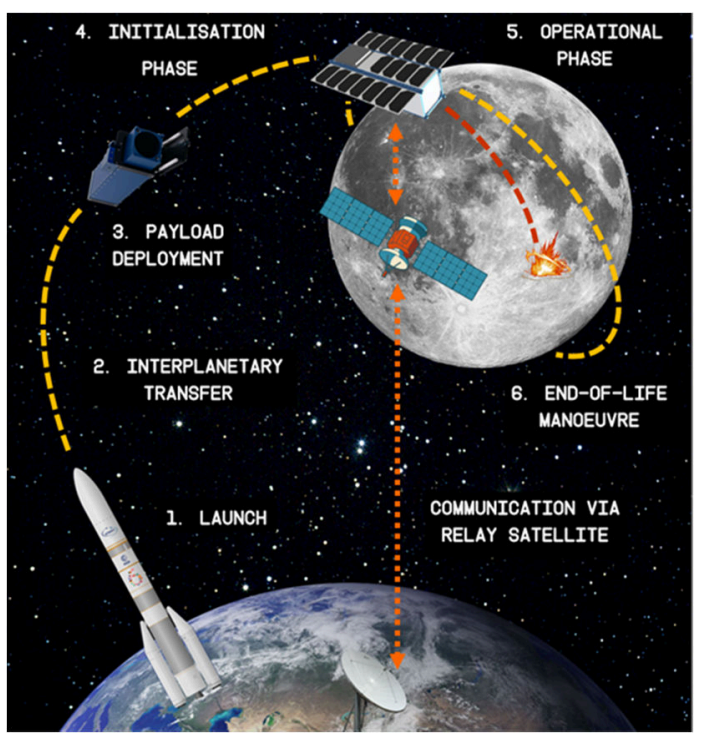

Figure 11: Overview of Mission Phases

\footnotetext{
${ }^{2}$ Signal to Noise Ratio
} 


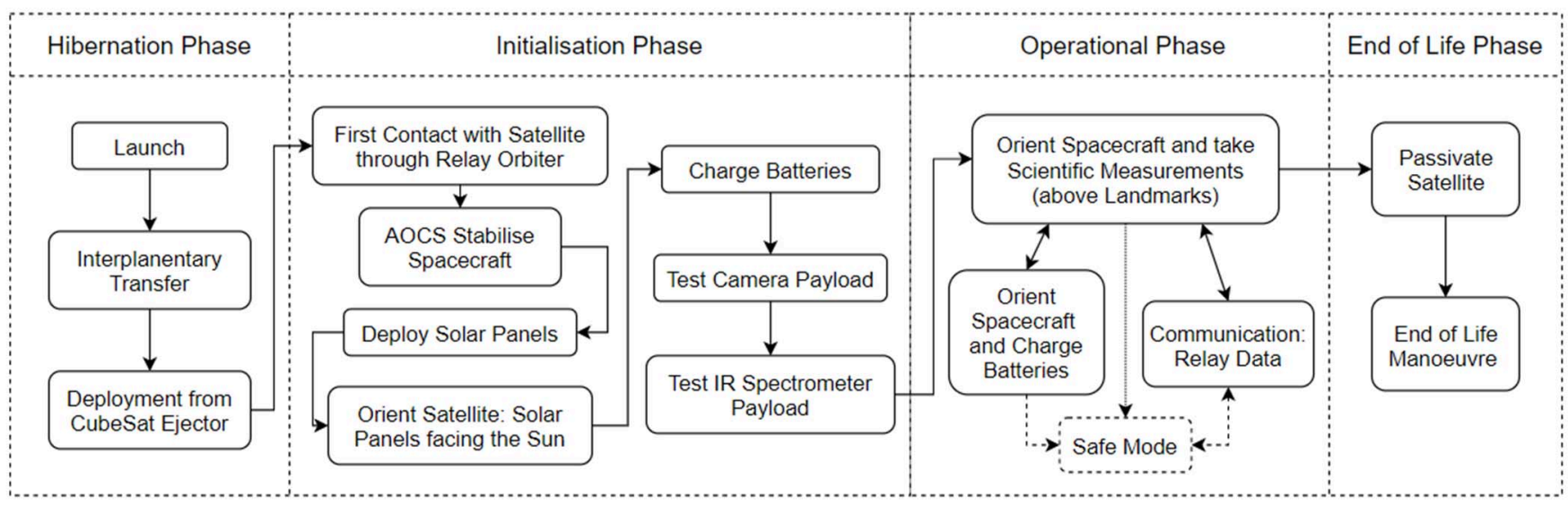

Figure 12: Overview of Mission CONOPS

After initialisation, once the satellite power is at its capacity, the satellite will proceed to the first landmark and take measurements using the camera and IR spectrometer. On average, the satellite will have 5 minutes to take measurements. To transmit the recorded data, the CubeSat will need to transmit for 4 orbits without taking further measurements. During that period, the payload sensors will not take any additional measurements. While the satellite is transmitting, its solar panels will continue to point towards the sun to charge the batteries. After all the data has been transmitted, the satellite will continue to the next landmark and begin the process again. The thruster will be needed for occasional orbit maintenance manoeuvres. The thruster will be fired when the satellite is in the sunlight to avoid overloading the satellite during eclipse periods.

\section{Environment}

The lunar orbit is a hostile operating environment. There is no atmosphere to protect satellites from the ionising radiation environment, galactic solar rays or solar flares. In addition, the satellite needs to operate in a vacuum with temperatures fluctuating between $119^{\circ} \mathrm{C}$ and $-173^{\circ} \mathrm{C}$. Even before the satellite reaches orbit, it must survive the vibrations and shocks associated with launch.

Radiation can have three main effects on CubeSat components, with Single Event Effects (SEEs) posing the greatest challenge. SEEs occur when high-energy particles traverse electronic components, causing software upsets, also known as Single Event Upsets (SEU), which include bit flips. In more severe cases, SEEs could include latch-ups, also known as Single Event Latch-ups (SEL), and gate ruptures, which can destroy a mission. The remaining two degradation effects from radiation are cumulative, causing the gradual degradation of electrical components. Total Ionising Dose occurs when continuous particle impacts create defects within oxides and Displacement Damage takes place when those incoming particles displace atoms in the semiconductor crystal lattice.

Even though all components selected in this CubeSat design, including the OpenKit, have been qualified for space flight, additional shielding from radiation is required and is difficult to implement. Radiation shielding is the most widely implemented method of protection against the effects but can be heavy and large. NASA Langley Research Centre has been developing radiation shields made from fibre metal laminates [50]. Several sheets of metallic materials with differing atomic numbers are layered using the Z-grading method to protect sensitive spacecraft electronics from ionizing radiation. These are lighter and more flexible than conventional shielding material, allowing the team to protect hard-to-shield locations. Currently this technology is at a relatively low technology readiness level (TRL), but since this mission is not due to launch until 2025, further developments could make this a viable solution.

Rather than including physical shielding, another method includes radiation hardening, which involves making electronic components more resistant to radiation damage. Although these types of fault avoidance techniques are robust and reliable, they increase power usage, costs and lead times while decreasing computational power. Alternatively, fault detection systems could be utilised. These methods impose fewer restrictions on power and computational power, and have reduced associated hardware costs, but have increased hardware and software complexity. SELENE's components could utilise error detection and correction techniques (EDAC), such as field-programmable gate array (FPGA)based EDAC, which protect against SEUs, or SEL protection systems which detect and isolate latch-up currents. Additionally, watchdog architectures [51] can be implemented. A watchdog subsystem monitors the system operations and restarts the system or puts the system in a safe mode if a fault is detected.

The MarCO mission opted for radiation tolerant electronics and a cascaded watchdog system in lieu of additional radiation shielding [52][53]. Whether the team choses to include additional shielding, radiation hardened or tolerant components, or utilise fault detection systems, will be a tradeoff between reliability, power, computational power, mass and cost. 
To decrease the cost of the operation phase and enhance the capabilities of the satellite, some degree of autonomy has to be included in a space mission. For this project, it would also increase the output of the scientific mission, as the data rate for communication is low and every transmission must be maximised. Aside from this, it is also important to overcome the delay in the transmission time that would make manual commanding of every satellite task infeasible. Therefore, as can be seen in the proposed concept of operations, there are several tasks that could be performed autonomously and onboard:

- Deployment of solar panels: One of the first tasks the satellite must perform after ejection towards its orbit is solar panel deployment, this will prevent the batteries from total discharge. It should be performed autonomously as the satellite will not have established communication with the relay satellite at the beginning of the mission.

- Satellite orientation guidance: The on-board guidance will identify when the satellite needs to recharge its batteries and reorient the satellite to face the Sun. It will also reorient the CubeSat when it is passing over a landmark or when safe mode is activated and manage the reference signals to OC's AOCS system.

- Orbit maintenance: Over time, the satellite deviates slightly from the desired orbit. This can be detected by the AOCS sensors and in response, a signal will be sent to the actuators to orient the spacecraft and activate the thruster.

- Detection of landmarks: From a preloaded file containing records of the landmarks of interest, the satellite will be able to detect if it is passing over a landmark. This will be performed using its on-board calculated position.

- On-board pre-processing of payload data: The limiting maximum data rate for the communication with the relay satellite emphasises the importance of minimising the amount of data to transfer. This can be achieved by selecting the best images per landmark and then compressing the data before transmission.

- End of life manoeuvre: At the end of the mission, the CubeSat thruster will perform a de-orbiting manoeuvre.

- $\quad$ Satellite status monitoring: The CubeSat will be able to monitor the status of every subsystem and actuate in accordance, e.g. triggering the safe mode if the power levels are too low.

The on-board flow control follows the designed operations. Each status prevents the operator from activating undesired actuators or sensors, while following the flow of the prepared procedures. It is possible to change the mode from any state to another with a command. If connectivity is lost, the operational phase state machine will safely stop current operations before transmitting an emergency signal and waiting until communications are restored. In this case, if the power reaches a predetermined low level, safe mode will be triggered, and the satellite will reorient to face the Sun.

In Figure 13, the blue regions represent the different phases of the CONOPS, while the yellow regions represent the three possible modes of operation. Nominally, the CubeSat will be in autonomous mode, but there are two other modes in case the operator has to take control of the satellite to implement corrections. In the operational phase, the CubeSat will wait until it passes over a landmark and then start recording data from the camera and the spectrometer. When the pass has finished, the gathered measurements will be processed and forwarded to the relay satellite, to be sent to the ground station.

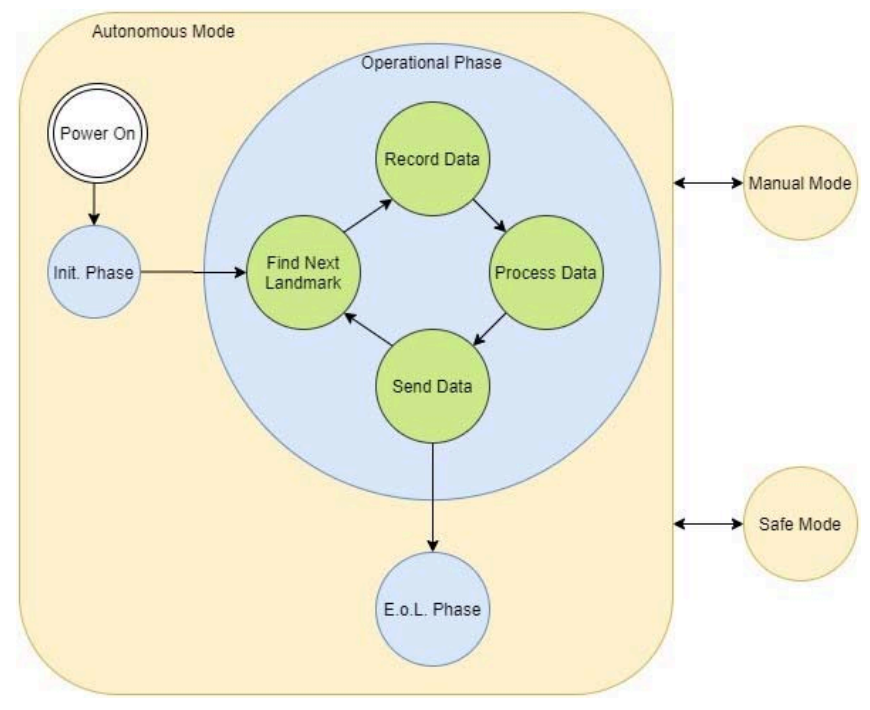

Figure 13: On-Board Flow Control

\section{End of Life Operations}

There is no doubt that a great deal of attention is usually given to planning and executing the designated operations of a space mission. However, it is also crucial to consider what happens to the satellite at the end of its lifetime.

Differing slightly from Earth-orbiting satellites, there are three main categories [54] when it comes to methods for disposing of lunar satellites:
1. Lunar Impact
2. Earth Re-entry
3. Graveyard Orbit Disposal

Due to the limitation of the 3U platform's mass, it is not possible to have enough propellant to eject the spacecraft from its operational orbit to another trajectory, either for an Earth re-entry disposal or for moving the satellite into one of the graveyard orbits. Thus, the easiest option will be the lunar impact strategy.

Unlike Earth satellites that could undergo orbital decay and 
deorbit, whereupon they can burn up in the atmosphere, the lunar impact strategy will guarantee impact with the lunar surface at the end of the disposal phase. Thus, it is clear that to avoid further damage, the impact has to be set in accordance with all mitigations and treaties related to the lunar environment, such as those stated in the United Nations Treaties and Principles on Outer Space [27]. Furthermore, the disposal has to avoid any interference with historical heritage sites, for example the respective landmarks for the mission, to preserve historical and scientific value of lunar artefacts located on ground [30] and natural resources that would provide knowledge and insights to the Moon's history.

\section{Discussion}

Below are outlined several lessons learned and thoughts emerging from the exercise of designing this $3 \mathrm{U}$ CubeSat.

\section{Additional Infrastructure}

The 3U CubeSat platform does not have enough volume or power to include a communications subsystem powerful enough to relay information directly from the lunar satellite to Earth. Therefore, any lunar CubeSat will need to account for a relay satellite to transmit data from the CubeSat to the ground stations.

Another issue regarding the small volume and computational power on-board the CubeSat is the management of information. This coupled with a very low communication data rate ( $4 \mathrm{kbps}$ imposed by the UKSEDS competition) increases the difficulty of communicating data. To address this problem, a potential solution would be to increase the onboard memory in the relay communication satellite. In this way, the communication satellite would act as a buffer which stores all the information gathered by the CubeSat and then forwards it to the ground whenever possible. This solution would decrease the need for more memory on-board the CubeSat and would reduce the computational consumption of the payload on-board the CubeSat.

\section{Limited Payload Options}

In earlier sections, this report identified commercially available spaceflight hardware which can be integrated within a $3 \mathrm{U}$ CubeSat platform. The payloads selected were required to be off-the-shelf products and take up minimal space in the CubeSat. This limits the available sensor options however the chosen sensors for camera and infrared spectrometer are both good examples weighing below $500 \mathrm{~g}$ and occupying less that $1 \mathrm{U}$ of the available space.

However, when considering the performance of the sensor, most commercial products that can be fit into a $3 \mathrm{U}$ CubeSat have notable drawbacks in their ability to capture and deliver meaningful science returns. For example, the standard IR sensor has a resolution of around hundreds of meters [55][42][56][57] which should be adequate for detecting large deposits of minerals or identifying the temperature variation across regions, but at the cost of impairing detection of smaller scale features. There are instruments with superior performance, notably NASA's recent project for the Lunar Compact InfraRed Imaging System (L-CIRiS) which is an instrument designed to capture high-spatial resolution thermal infrared images of the moon [58]. The detailed specification of the payload is not yet known, however its predecessor from which it will be adapted - the CIRiS instrument [59], has a spatial resolution of less than $60 \mathrm{~m}$ but a volume larger than $3 \mathrm{U}$ for the payload alone.

In general, the average size of high-performance sensors is beyond the capacity afforded by a $3 \mathrm{U}$ CubeSat. Even though there are options that are small enough, their measurement quality is drastically worse and not worth the reduction in volume or mass.

\section{Attitude and Orbit Control Systems}

Attitude Determination and Control systems (ADCS) have been extensively employed in LEO CubeSats [60] and several options exist for fully integrated ADCS units (i.e. providing sensors and actuators) for interplanetary CubeSats. MarCO [61][62] mission has been provided by Blue Canyon Technologies (BCT) XACT modules for deep space [63], able to provide $\pm 0.003 \mathrm{deg}(1 \sigma)$ for two axes and $\pm 0.007 \mathrm{deg}$ $(1 \sigma)$ for third axis of pointing accuracy within the $0.5 \mathrm{U}$ CubeSats standard. SELENE mission could also benefit from this unit for its science phase.

As mentioned, SELENE orbit maintenance also requires active control to stabilize the orbit, considering $10-15 \mathrm{~m} / \mathrm{s}$ per month. Therefore, SELENE will be provided by an on-board propulsion system able to provide the required $\Delta \mathrm{v}$ for orbit maintenance. Several options exist for this purpose: VACCO Industries has provided MarCO mission a $2 \mathrm{U}$ cold gas propulsion system [64] and could potentially provide SELENE with a warm gas Propulsion Unit for CubeSats (PUC), scalable from $0.14 \mathrm{U}$ to $1 \mathrm{U}$, providing sufficient $\Delta \mathrm{v}$ capabilities [65]. Alternatively, the cold iodine thruster produced by ThrustMe, discussed earlier in the paper, would also meet the $\Delta v$ requirements and would fit within a form factor of $0.5 \mathrm{U}$.

\section{Data Efficiency}

In order to allow for design flexibility given the constraints of computing power and data transmission capabilities, the efficiency in storage and transmission of the data gathered by scientific instruments must be carefully considered. If powerful processing capabilities are readily available, they can be applied to offset data transfer requirements. Similarly, a higher data rate can be applied to lower the burden on onboard systems to process data by streaming raw data to ground stations more readily able to process the data. The best candidate for these considerations is the data captured by the onboard camera which accounted for $\sim 80 \%$ of the data budget in our proposed payload design. 
Lossless compression algorithms, those which reversibly reduce the size of data without losing information, are ubiquitous in computing in applications which seek to optimise storage space and accelerate data transfer. Due to the requirement to conduct science based on the returned data, only lossless compression can be considered. Due to the limited colour palette of the lunar surface, PNG-8 [66] may prove useful over the more common 24 bit variant, allowing for image sizes to be reduced to a third of their native format while still displaying the same 256 grayscale colours. Other general-purpose lossless compression algorithms such as variations of Lempel-Ziv compression [67] could aid in further reductions although the particular variant would have to be chosen based on the aforementioned trade-offs between available computational and communication capabilities.

Recent advancements by smartphone manufacturers have brought machine vision to the fore as a method for automatically analysing and optimising image quality. Technologies such as Google's Night Sight and Apple's Deep fusion demonstrate capabilities for identifying, selecting and merging the optimal features from a set of images to produce the highest fidelity representation possible. The latter technology from Apple is aided by dedicated neural network hardware on their A13 Bionic chip [68]. Such approaches can be used for identifying high quality images and rejecting those of insufficient quality although going beyond that to creating superior composite images may be undesirable due to the inherent inaccuracy of the enhanced scientific data returned.

A limiting factor in the application of even mature hardware designed for terrestrial use is the harmful impacts of radiation in the extra-terrestrial environment. This environment often prohibits the use of cutting-edge COTS hardware, instead requiring radiation-hardened specialty equipment which must sacrifice performance for reliability. Experiments such as NASA's PhoneSats [69] may shed light on the ability of COTS hardware to withstand the effects of radiation for short missions.

\section{Technology Demonstration Mission}

The specific data returned by the scientific operations of this satellite do not offer much greater insight than can already be attained through existing instruments. Rather, the value of the satellite will most likely be as part of a constellation or as a technology demonstrator. For instance, the effectiveness of the proposed IR sensor and X-Band SAR is well-suited for evaluation as part of this platform.

\section{Conclusion}

The ubiquity of CubeSats in geocentric applications has made it clear that they are inextricably linked to the future of space travel as an enabling technology, providing services which will power the advancement of space exploration. Moving beyond Earth-based deployments to lunar missions is a natural and achievable progression for the technology.
However, the platform still faces limitations in available volume which impacts payload selection, power and data transfer capabilities.

These limitations are not insurmountable, but they do necessitate the use of external orbit injection and supporting infrastructure such as relay satellites to extend communication.

The CubeSat design documented in this paper seeks to push the boundaries of the 3U platform's capabilities given the current state of the art. The consistent miniaturisation of technology may mean that this form factor will be capable of even greater science in the future but for the present, a $6 \mathrm{U}$ platform may provide a greater scientific return by alleviating the constraints imposed by the restrictive $3 \mathrm{U}$ volume.

Regardless of the optimal size, the CubeSat has been proven to allow rapid, low-cost development while still being capable of powering critical satellite-based services, contributing to large constellations and serving as a technology demonstrator to accelerate advancements for both terrestrial and extra-terrestrial applications. 


\section{APPENDICES}

\section{A. LUNAR LANDMARKS}

Historic lunar landmark provided by the competition organizers (UKSEDS and OC):

\begin{tabular}{l|c} 
Landmark & Co-Ordinates \\
\hline $\begin{array}{l}\text { Apollo 11 Landing Site - Mare } \\
\text { Tranquillitatis }\end{array}$ & $00.67^{\circ} \mathrm{N}, 23.47^{\circ} \mathrm{E}$ \\
\hline Lunokhod 1 Landing Site & $38.24^{\circ} \mathrm{N}, 35.00^{\circ} \mathrm{W}$ \\
\hline $\begin{array}{l}\text { Apollo 15 Landing Site - } \\
\text { Hadley/Appennines }\end{array}$ & $26.13^{\circ} \mathrm{N}, 3.63^{\circ} \mathrm{E}$ \\
\hline Chang'e 3 Landing Site & $44.12^{\circ} \mathrm{N}, 19.51^{\circ} \mathrm{W}$ \\
\hline Chang'e 4 Landing Module & $45.44^{\circ} \mathrm{S}, 177.60^{\circ} \mathrm{E}$ \\
\hline SMART-1 Impact Site & $34.26^{\circ} \mathrm{S}, 46.19^{\circ} \mathrm{W}$ \\
\hline Chandrayaan-1 Impact Site & $89.76^{\circ} \mathrm{S}, 39.40^{\circ} \mathrm{W}$ \\
\hline SELENE Main Orbiter Impact Site & $65.50^{\circ} \mathrm{S}, 80.50^{\circ} \mathrm{E}$ \\
\hline Beresheet Impact Site & $32.60^{\circ} \mathrm{N}, 19.35^{\circ} \mathrm{E}$ \\
\hline Mons Huygens & $19.92^{\circ} \mathrm{N}, 2.86^{\circ} \mathrm{W}$
\end{tabular}

\section{B. Mission ASSUMPTIONS AND REQUIREMENTS}

\section{List of Assumptions}

The satellite payload shall be integrated with Open Cosmos' $3 \mathrm{U}$ platform with the following characteristics:

- Available payload mass: $2 \mathrm{~kg}$, total satellite mass: 6 $\mathrm{kg}$

- Communications: omni-directional, S-band antenna

○ Transmitter (Tx) Frequency: $2245 \mathrm{MHz}$ (S-band)

- Receiver (Rx) Frequency: 2025 MHz (Sband)

- Tx Output Power: 2W (33 dBm)

- Antenna Gain: $6.9 \mathrm{~dB}$

- System Losses: $5 \mathrm{~dB}$

- Power: total of 18 solar cells (14 on two doubledeployable solar panels and 4 on the main body of the satellite)

- Surface Area of each Solar Cell: $26.5 \mathrm{~cm} 2$

- Efficiency: $28 \%$

- Yearly Degradation: 0.02

○ Inherent Degradation factor: 0.77

- Battery cells

○ Nominal Cell Capacity: 11.4 Wh each

- Lowest Nominal Voltage: $3 \mathrm{~V}$

- Cell Max Voltage: $4.2 \mathrm{~V}$

- Cell Min Voltage: $2.5 \mathrm{~V}$

○ Yearly Degradation: 0.14

- Attitude Dynamics Control System (ADCS): 3 reaction wheels (pointing accuracy of 0.5 degrees and sun sensors)
A Lunar relay satellite will be used to facilitate communication between the CubeSat and Earth throughout the mission lifetime. The following Lunar relay satellite characteristics were provided by the competition organisers:

- Lunar Orbit Altitude: $100 \mathrm{~km}$

- Uplink: omni-directional, S-band antenna with a data rate of $4 \mathrm{kbps}$

- Downlink: $0.75 \mathrm{~m}$ diameter directional parabolic Ka-band reflector antenna

- Ground Station Noise: $12.6 \mathrm{~dB} / \mathrm{K}$

- Communication latencies shall be assumed to be negligible

The Lunar transfer manoeuvre shall be provided by the competition organisers and can be omitted from analysis.

The mission team determined the satellite will launch in 2025 and thus any technologies with TRL 5 or above will be considered for the satellite design.

\section{Mission Requirements}

\begin{tabular}{|l|l|}
\hline MR-1 & $\begin{array}{l}\text { The satellite shall have a mission timeline of } \\
\text { 2 years maximum with an expected } \\
\text { operational time period of 3 months }\end{array}$ \\
\hline MR-2 & $\begin{array}{l}\text { The launch provider and launch date shall be } \\
\text { selected by the team, with justifications }\end{array}$ \\
\hline MR-3 & $\begin{array}{l}\text { The orbit should allow the spacecraft to } \\
\text { maximize the number of revisits to each } \\
\text { lunar landmark during the simulation } \\
\text { duration }\end{array}$ \\
\hline
\end{tabular}

Operations Requirements

\begin{tabular}{|l|l|}
\hline OR-S-1 & $\begin{array}{l}\text { The system shall be able to detect, identify } \\
\text { and analyze information from historic lunar } \\
\text { landmarks }\end{array}$ \\
\hline OR-S-2 & $\begin{array}{l}\text { The satellite shall be able to successfully } \\
\text { deploy from the CubeSat deployer }\end{array}$ \\
\hline OR-C-3 & $\begin{array}{l}\text { Primary Communication with Earth shall be } \\
\text { facilitated through a Lunar relay satellite to } \\
\text { downlink payload data }\end{array}$ \\
\hline OR-C-4 & $\begin{array}{l}\text { The CubeSat shall be able to communicate } \\
\text { with typically available ground station(s) } \\
\text { and/or the Lunar Relay Satellite for } \\
\text { telemetry, tracking, and control (TT\&C) } \\
\text { purposes }\end{array}$ \\
\hline OR-S-5 & $\begin{array}{l}\text { The satellite shall be capable of performing } \\
\text { the necessary attitude control to maintain the } \\
\text { desired Lunar orbit }\end{array}$ \\
\hline OR-S-6 & $\begin{array}{l}\text { The satellite shall have prior knowledge of } \\
\text { where the Lunar landmark sites are located }\end{array}$ \\
\hline OR-S-7 & $\begin{array}{l}\text { The satellite shall have an End of Life } \\
\text { strategy to minimise the impact to scientific } \\
\text { return of current and future Lunar missions }\end{array}$ \\
\hline
\end{tabular}


Constraints

\begin{tabular}{|c|c|}
\hline CR-S-1 & $\begin{array}{l}\text { The satellite payload mass shall not exceed } 2 \\
\mathrm{~kg}\end{array}$ \\
\hline CR-S-2 & $\begin{array}{l}\text { The payload shall not exceed the OpenKit } \\
\text { available volume of } 1.5 \mathrm{U}\end{array}$ \\
\hline CS-S-3 & $\begin{array}{l}\text { The payload subsystem shall be integrated } \\
\text { with Open Cosmos' } 3 \mathrm{U} \text { satellite platform }\end{array}$ \\
\hline CR-C-4 & $\begin{array}{l}\text { Downlink and uplink data rate between the } \\
\text { CubeSat and the Lunar relay satellite shall } \\
\text { be limited to } 4 \mathrm{kbps}\end{array}$ \\
\hline CR-P-5 & $\begin{array}{l}\text { The power used by the payload subsystem } \\
\text { shall not exceed } 18.5 \mathrm{~W}\end{array}$ \\
\hline CR-E-6 & $\begin{array}{l}\text { The satellite shall maintain all components } \\
\text { within their respective operating temperature } \\
\text { ranges while in operation }\end{array}$ \\
\hline CR-E-7 & $\begin{array}{l}\text { The satellite shall always maintain all } \\
\text { components within their respective survival } \\
\text { temperature ranges, other than operation, } \\
\text { after launch }\end{array}$ \\
\hline CR-E-8 & $\begin{array}{l}\text { The satellite shall be able to operate within } \\
\text { the hard vacuum of space }\end{array}$ \\
\hline CR-E-9 & $\begin{array}{l}\text { The satellite shall be able to operate within } \\
\text { an ionising radiation environment, } \\
\text { from galactic solar rays and solar flares, and } \\
\text { mitigate against these effects }\end{array}$ \\
\hline CR-E-10 & $\begin{array}{l}\text { The satellite shall pass the sinusoidal } \\
\text { vibration test as per the tables in Appendix } \\
\text { E, simulating launch conditions }\end{array}$ \\
\hline CR-E-11 & $\begin{array}{l}\text { The satellite shall pass the random vibration } \\
\text { tests as per the tables in Appendix E, } \\
\text { simulating launch conditions }\end{array}$ \\
\hline CR-R-12 & $\begin{array}{l}\text { The satellite shall consider the Outer Space } \\
\text { Treaty }\end{array}$ \\
\hline CR-R-13 & $\begin{array}{l}\text { The satellite shall ensure immediate } \\
\text { termination of radio emissions by tele- } \\
\text { command, whenever required under the } \\
\text { provisions of ITU regulations }\end{array}$ \\
\hline CR-R-14 & $\begin{array}{l}\text { The approval time for a communication } \\
\text { frequency by the ITU shall be considered }\end{array}$ \\
\hline CR-S-15 & $\begin{array}{l}\text { The wait time for a launch by the selected } \\
\text { launch provider shall be considered }\end{array}$ \\
\hline
\end{tabular}

\section{ACKNOWLEDGEMENTS}

We would like to thank UKSEDS, SSPI and Open Cosmos for organising the Satellite Design Competition 2019-2020 and continuing to run the competition despite challenging circumstances. We are grateful for the support we received throughout the year; competing was a very valuable experience. We would also like to thank Momentus Space for their contribution to the competition and this paper.

\section{REFERENCES}

[1] E. Kulu, "What is a nanosatellite?," Nanosats Database, 2020. https://www.nanosats.eu/cubesat (accessed Oct. 16, 2020).

[2] E. Kulu, "World's largest database of nanosatellites, over 2700 nanosats and CubeSats," Nanosats Database, 2020. https://www.nanosats.eu/ (accessed Oct. 16, 2020).

[3] ESA Space Debris Office, "ESA's Annual Space Environment Report," 2020. Accessed: Oct. 16, 2020. [Online]. Available: www.esa.int.

[4] E. Howell, "CubeSats: Tiny Payloads, Huge Benefits for Space Research," Space.com, 2018 https://www.space.com/34324-cubesats.html (accessed Oct. 16, 2020).

[5] International Space Exploration Coordination Group, "The Global Exploration Roadmap," 2018. Accessed: Jul. 20, 2020. [Online]. Available: www.globalspaceexploration.org.

[6] A. Mishkin, L. Young, D. Korth, and T. LeBlanc, "Human-robotic missions to the moon and mars: Operations design implications," in IEEE Aerospace Conference Proceedings, 2007, doi: 10.1109/AERO.2007.352960.

[7] B. Hurley, "NASA 2024 Moon Mission Calls for CubeSats," Tech Briefs, 2020. https://www.techbriefs.com/component/content/arti cle/tb/stories/blog/36282 (accessed Oct. 16, 2020).

[8] A. Batista, E. Gomez, H. Qiao, and K. E. Schubert, "Constellation Design of a Lunar Global Positioning System Using CubeSats and Chip-Scale Atomic Clocks," in WorldComp, 2012.

[9] P. Bugryniec, "CubeSat: The Need for More Power to Realise Telecommunications," 2016.

[10] UKSEDS, "Satellite Design Competition 20192020," 2020. https://ukseds.org/aurora/?p=home\&event_id=51 (accessed Oct. 16, 2020).

[11] UKSEDS, "Satellite Design Competition 19/20 Rules and Requirements," UKSEDS, 2019. https://drive.google.com/file/d/12oH2DozsXK9L6t 94KZ-E4D8GeVBeM-1/view (accessed Apr. 06, 
2020).

[12] A. T. Klesh et al., "MarCO: Early Operations of the First CubeSats to Mars," 2018.

[13] D. R. Graham, J. A. Englander, N. J. Rattenbury, and J. E. Cater, "Low-Thrust Transfer to Interplanetary Trajectories from Lunar Trajectories with Rideshare," in AAS/AIAA Astrodynamics Specialist Conference, 2020.

[14] C. Cappelletti and D. Robson, "CubeSat missions and applications," in Cubesat Handbook, Elsevier, 2020, pp. 53-65.

[15] ESA, "Ariane 6,", 2020. https://www.esa.int/Enabling_Support/Space_Trans portation/Launch_vehicles/Ariane_6 (accessed Jul. 20, 2020).

[16] C. Henry, "Arianespace targets 2023 for lunar Ariane 6 rideshare mission," SpaceNews, 2019. https://spacenews.com/arianespace-targets-2023-

for-lunar-ariane-6-rideshare-mission/ (accessed Jul. 20, 2020).

[17] United Launch Alliance, “Atlas V," 2019. https://www.ulalaunch.com/rockets/atlas-v

(accessed Jul. 20, 2020).

[18] Momentus Space, "Services," 2020. https://momentus.space/services/ (accessed Oct. 16, 2020).

[19] V. Domingo, B. Fleck, and A. I. Poland, "The SOHO Mission: An Overview," in The SOHO Mission, Springer Netherlands, 1995, pp. 1-37.

[20] P. McNamara and G. Racca, "Introduction to LISA Pathfinder," 2009.

[21] R. Armellin, P. Di Lizia, G. Di Mauro, M. Rasotto, and M. Landgraf, "Disposal strategies for spacecraft in Lagrangian Point Orbits,” 2014.

[22] D. Spergel et al., "Wide-Field InfrarRed Survey Telescope-Astrophysics Focused Telescope Assets WFIRST-AFTA 2015 Report," arXiv:1503.03757v2 [astro-ph.IM], Mar. 2015, Accessed: Oct. 16, 2020. [Online]. Available: http://arxiv.org/abs/1503.03757.

[23] L. Puig et al., "The Phase A study of the ESA M4 mission candidate ARIEL," Exp. Astron., vol. 46, no. 1, pp. 211-239, Nov. 2018, doi: 10.1007/s10686018-9604-3.

[24] D. Folta and D. Quinn, "Lunar Frozen Orbits," in AIAA/AAS Astrodynamics Specialist Conference and Exhibit, Aug. 2006, doi: 10.2514/6.2006-6749.

[25] M. Beckman, "Mission Design for the Lunar Reconnaissance Orbiter," in 29th ANNUAL AAS GUIDANCE AND CONTROL CONFERENCE, 2006.

[26] C. Nieto-Peroy and M. R. Emami, "CubeSat Mission:
From Design to Operation," Appl. Sci., 2019.

[27] United Nations Office for Outer Space Affairs, "The Outer Space Treaty," 1966. https://www.unoosa.org/oosa/en/ourwork/spacelaw/ treaties/introouterspacetreaty.html (accessed Jul. 20, 2020).

[28] IADC, "IADC Space Debris Mitigation Guidelines," 2007.

[29] United Nations Office for Outer Space Affairs, "Space Debris Mitigation Guidelines of the Committee on the Peaceful Uses of Outer Space," 2010.

[30] J. Wiles, 'NASA's Recommendations to SpaceFaring Entities: How to Protect and Preserve the Historic and Scientific Value of U.S. Government Lunar Artifacts," $\quad$ NASA, 2013 http://www.nasa.gov/directorates/heo/library/reports /lunar-artifacts.html (accessed Oct. 16, 2020).

[31] ESA, "Margin philosophy for science assessment studies," 2012. Accessed: Oct. 16, 2020. [Online]. Available: www.esa.int.

[32] GomSpace, "NanoCam C1U Datasheet Camera payload for nano-satellites," 2018.

[33] M. Nasir, G. Christine, and A. Rashid, "The JPEG Lossless Image Compression Standards," pp. 733 745, Jan. 2005, doi: 10.1016/B978-0121197926/50106-6.

[34] W. W. Mendell and F. J. Low, "Preliminary results of the Apollo 17 infrared scanning radiometer," Moon, vol. 9, no. 1-2, pp. 97-103, Mar. 1974, doi: 10.1007/BF00565396.

[35] D. A. Paige et al., "The lunar reconnaissance orbiter diviner lunar radiometer experiment," Space Sci. Rev., vol. 150, no. 1-4, pp. 125-160, Jan. 2010, doi: $10.1007 / \mathrm{s} 11214-009-9529-2$.

[36] J. P. Williams, D. A. Paige, B. T. Greenhagen, and E. Sefton-Nash, "The global surface temperatures of the moon as measured by the diviner lunar radiometer experiment," Icarus, vol. 283, pp. 300-325, Feb. 2017, doi: 10.1016/j.icarus.2016.08.012.

[37] S. Beardsley and D. Heather, "Remote Sensing of the Moon: The Past, Present and Future," in 4th International Conference on the Exploration and Utilisation of the Moon, 2000, Accessed: Oct. 16, 2020. [Online]. Available: https://www.researchgate.net/publication/23451525 0 Remote_Sensing_of_the_Moon_The_Past_Prese nt_and_Future.

[38] B. H. J. Moore, J. M. Boyge, G. G. Schaber, D. H. Sgott, and H. W. Menard, "Lunar Remote Sensing and Measurements," $1980 . \quad$ doi: https://doi.org/10.3133/pp1046B. 
[39] S. Jin, S. Arivazhagan, and H. Araki, "New results and questions of lunar exploration from SELENE, Chang'E-1, Chandrayaan-1 and LRO/LCROSS," Adv. Sp. Res., vol. 52, no. 2, pp. 285-305, 2013, doi: 10.1016/j.asr.2012.11.022.

[40] W. Hao, F. Li, C. Xiao, J. Yan, and M. Ye, "Understanding the Moon's internal structure through moonquake observations and remote sensing technologies," Science China Earth Sciences, vol. 61, no. 8. Science in China Press, pp. 995-1006, Aug. 01, 2018, doi: 10.1007/s11430-017-9197-4.

[41] J. B. Adams, "Visible and near-infrared diffuse reflectance spectra of pyroxenes as applied to remote sensing of solid objects in the solar system," $J$. Geophys. Res., vol. 79, no. 32, pp. 4829-4836, Nov. 1974, doi: 10.1029/jb079i032p04829.

[42] R. K. Jagpal, "Calibration and in-orbit performance of the Argus 1000 spectrometer - the Canadian pollution monitor," J. Appl. Remote Sens., vol. 4, no. 1, p. 049501, Jan. 2010, doi: 10.1117/1.3302405.

[43] A. Freeman, "Design Principles for Smallsat SARs," in Small Satellite Conference 2018, 2018, Accessed: Jul. 20, 2020. [Online]. Available: https://www.researchgate.net/publication/32690161 8_Design_Principles_for_Smallsat_SARs.

[44] S. W. Paek, S. Balasubramanian, S. Kim, and O. de Weck, "Small-satellite synthetic aperture radar for continuous global biospheric monitoring: A review," Remote Sensing, vol. 12, no. 16. MDPI AG, p. 2546, Aug. 01, 2020, doi: 10.3390/RS12162546.

[45] ThrustMe, "The I2T5," 2020. https://www.thrustme.fr/products/i2t5 (accessed Oct. $16,2020)$.

[46] Open Cosmos, "3U OpenKit," 2020. https://www.open-cosmos.com/openkit-store/p/3u (accessed Oct. 16, 2020).

[47] ISIS - Innovative Solutions in Space B.V., "Antenna Systems ," 2020. Accessed: Oct. 16, 2020. [Online]. Available: $\quad$ https://www.isispace.nl/wpcontent/uploads/2019/08/ISIS-Antenna-SystemsBrochure-V2R-web.pdf.

[48] J. Todd, D. J. Hei, W. S. Guion, and P. Shapiro, "Communications support for lunar missions using the TDRS II system," Acta Astronaut., vol. 30, no. C, pp. 279-287, Jul. 1993, doi: 10.1016/00945765(93)90121-C.

[49] Electronic Communications Committee, "ECC REPORT 152 THE USE OF THE FREQUENCY BANDS 27.5-30.0 GHz AND 17.3-20.2 GHz BY SATELLITE NETWORKS," 2010.

[50] Langley Research Center, “Atomic Number (Z)Grade Radiation Shields from Fiber Metal Laminates,” 2015. Accessed: Dec. 08, 2020.
[Online]. Available: http://technology.nasa.gov/.

[51] J. Beningo, "A Review of Watchdog Architectures and their Application to Cubesats," 2010.

[52] eoPortal Directory, "MarCO," eoPortal, 2020. https://directory.eoportal.org/web/eoportal/satellitemissions $/ \mathrm{m} / \mathrm{marco \# spacecraft} \mathrm{(accessed} \mathrm{Dec.} \mathrm{08,}$ 2020).

[53] S. Asmar and S. Matousek, "Mars cube one (MarCO) shifting the paradigm in relay deep space operations," in SpaceOps 2016 Conference, 2016, doi: 10.2514/6.2016-2483.

[54] H. Klinkrad and U. M. Bohlmann, "Requirements on Space Debris Mitigation for ESA Projects," in 48th session of the Legal Subcommittee of the UN Committee on the Peaceful Uses of Outer Space, 2009.

[55] Thor Technology Inc., "Argus 2000 IR Spectrometer Owner's Manual,” 2018. Accessed: Jul. 20, 2020. [Online]. Available: www.thothx.com.

[56] Collins Aerospace, "MIL RUGGED, HIGH SENSITIVITY AND SMALL SWAP INGAAS SWIR CAMERA,” 2020. Accessed: Jul. 20, 2020. [Online]. Available: www.marines.mil.

[57] P. E. Clark et al., "The First Deep Space Cubesat Broadband IR Spectrometer, Lunarcubes, and the Search for Lunar Volatiles.” Accessed: Jul. 20, 2020. [Online].

Available: https://ntrs.nasa.gov/search.jsp?R=20170002429.

[58] D. P. Osterman, P. O. Hayne, T. Kampe, G. Reavis, and R. Warden, "L-CIRiS, an instrument for highspatial resolution thermal infrared imaging on the lunar surface," in 51st Lunar and Planetary Science Conference, 2020, doi: 10.1117/12.2531404.

D. P. Osterman, P. Hayne, R. Warden, G. Reavis, T. Kampe, and S. Mitchell, "CIRiS, a CubeSatcompatible, imaging radiometer for earth science and planetary missions," in CubeSats and SmallSats for Remote Sensing III, Aug. 2019, vol. 11131, p. 14, doi: $10.1117 / 12.2531404$.

[60] X. Xia et al., "NanoSats/CubeSats ADCS survey," in Proceedings of the 29th Chinese Control and Decision Conference, CCDC 2017, Jul. 2017, pp. 5151-5158, doi: 10.1109/CCDC.2017.7979410.

[61] S. Palo, G. Stafford, and A. Hoskins, "An agile multiuse nano star camera for constellation applications," 2013.

[62] J. Schoolcraft, A. Klesh, and T. Werne, "MarCO: Interplanetary mission development on a cubesat scale," in SpaceOps 2016 Conference, 2016, doi: 10.2514/6.2016-2491.

[63] Blue Canyon Technologies, "Blue Canyon Technologies - Components," 2020. 
https://bluecanyontech.com/components (accessed Oct. 16, 2020).

[64] VACCO, "JPL MarCO Micro CubeSat Propulsion System ," 2020. https://cubesat-propulsion.com/jplmarco-micro-propulsion-system/ (accessed Oct. 16, 2020).

[65] CU Aerospace, "Small-Satellite Propulsion Unit for CubeSats (PUC),", 2020. http://www.cuaerospace.com/technologyproducts/compact-small-satellite-propulsion-unitcubesats (accessed Oct. 16, 2020).

[66] D. Duce, "Portable Network Graphics (PNG) Specification (Second Edition)," 2003. Accessed: Oct. 16, 2020. [Online]. Available: https://www.w3.org/TR/PNG/.

[67] J. Ziv and A. Lempel, "A Universal Algorithm for Sequential Data Compression," IEEE Trans. Inf. Theory, vol. 23, no. 3, pp. 337-343, 1977, doi: 10.1109/TIT.1977.1055714.

[68] M. Owen, "More power with less: Apple's A13 Bionic is faster and more power efficient," AppleInsider, 2019. https://appleinsider.com/articles/19/09/11/morepower-with-less-apples-a13-fusion-is-faster-andmore-power-efficient (accessed Oct. 16, 2020).

[69] NASA, "Phonesat The Smartphone Nanosatellite," 2013.

http://www.nasa.gov/centers/ames/engineering/proj ects/phonesat.html (accessed Oct. 16, 2020).

\section{BIOGRAPHY}

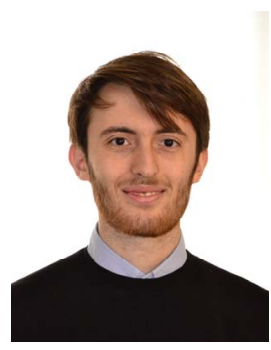

Andrea Bellome received the B.Sc. degree in Aerospace Engineering from La Sapienza - University of Rome, Italy, in July 2018 and the M.Sc. in Space Engineering from the University of Surrey, Guildford, U.K., in September 2019 with a thesis regarding multi- impulses mission optimization with Differential Algebra. He is currently pursuing a Ph.D. in Aerospace Engineering in collaboration with Airbus Defence \& Space at Cranfield University, Cranfield, U.K. His research interests include spacecraft trajectory optimization and mixed-integer space trajectory design.

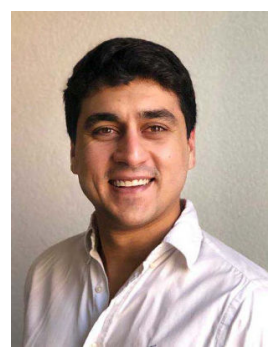

Aydin Nakhaee-zadeh Gutierrez received his $B$.S. degree in Aerospace Engineering within the field of air navigation from the University Rey Juan Carlos and his double degree Master in Space Science and Technology from LTU and Astronautics and Space Engineering from Cranfield University. He has experience in system control design mainly for UAVS and satellites and has been part of different space educational projects.

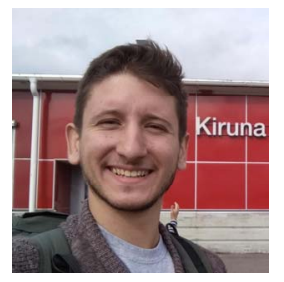

Guillermo Zaragoza Prous received his B.S. degree in Computer Engineering and his M.Sc. degree in Automatics and Robotics from the Technical University of Madrid and his Space Master double degree in Space Science and Technology from LTU and Astronautics and Space Engineering from Cranfield University. He has experience with robotic and space systems throughout a variety of student projects and work-related experience.

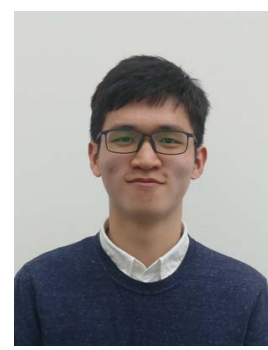

Louis Ji Hong, LENG is an MSc graduate from the Cranfield University, UK with a degree in Astronautics and Space Engineering, major in payload engineering with a focus on Earth observation purpose. He pursues his postgraduate study in space after obtaining a BEng in Aerospace Engineering from the Swansea University, UK in 2019. 


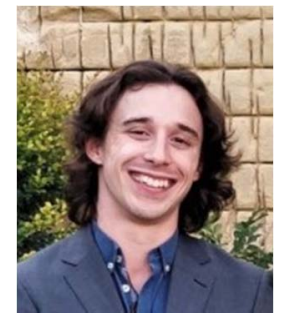

Matthew Coyle received a bachelor's degree in Computer Games Development from the University of Limerick, Ireland, in 2016. Since then he has worked as a software engineer primarily involved in green field projects across banking, transport and simulation with a focus on best practices, process improvement, automation and rapid prototyping.

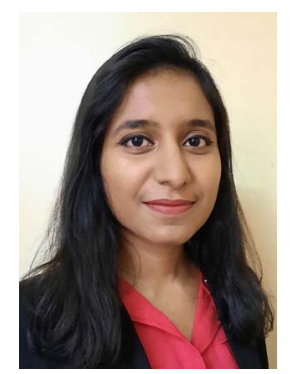

Sharon D'Souza received a B.Tech Degree in Aerospace Engineering from Alliance University, India in June 2019. She recently graduated with a M.Sc. Degree in Astronautics and Space Engineering from Cranfield University. Her areas of interest are systems engineering and space biotechnology.

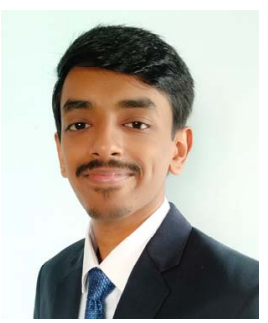

Suchetan Mummigatti has a bachelor's degree in Aerospace Engineering from Alliance University, Bangalore, India, in July 2019. He also has a MSc in Astronautics and Space Engineering from Cranfield University, UK, 2020, with his thesis on Multi-perceptual modalities message delivery module: MAILbox. He has previously interned at Indian Space Research Organisation (ISRO) working in flight dynamics and spacecraft structures division. He has combined experience in astrophysics and astronautics and has worked on multiple projects.

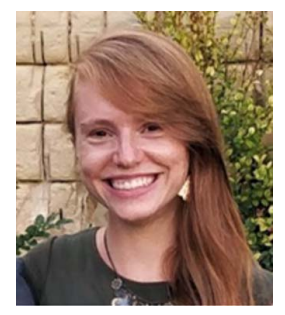

Zaria Serfontein received her BEng in Aeronautical Engineering from the University of Limerick, Ireland in 2015 and her MSc in Astronautics and Space Engineering from Cranfield University, UK in 2018 with a thesis investigating the scalability of Cranfield's De-Orbit Drag Sails. She is currently pursuing a PhD in Aerospace at Cranfield University, UK, focused on the further development and commercialisation of Cranfield's family of Drag Augmentation Systems. Her research interests include sustainable space, mechanical design and material science. 


\title{
Cranfield University
}

2021-06-07

\section{Application of nanosatellites for lunar missions}

\author{
Bellome, Andrea
}

IEEE

Bellome A, Nakhaee-Zadeh A, Zaragoza Prous G, et al., (2021) Application of nanosatellites for lunar missions. In: IEEE Aerospace Conference (AeroConf 2021), 6-20 March 2021, Big Sky, MA, USA

https://doi.org/10.1109/AERO50100.2021.9438417

Downloaded from Cranfield Library Services E-Repository 